\title{
PpCRN7 and PpCRN20 of Phythophthora parasitica regulate plant cell death leading to enhancement of host susceptibility
}

Heros J. Maximo ${ }^{1 \dagger}$, Ronaldo J. D. Dalio ${ }^{1 \dagger}$, Renata O. Dias ${ }^{2}$, Celso G. Litholdo Jr ${ }^{1}$, Henrique L. Felizatti ${ }^{3}$ and Marcos A. Machado ${ }^{1 *}$ (i)

\begin{abstract}
Background: Phytophthora species secrete cytoplasmic effectors from a family named Crinkler (CRN), which are characterised by the presence of conserved specific domains in the $\mathrm{N}$ - and C-terminal regions. P. parasitica causes disease in a wide range of host plants, however the role of CRN effectors in these interactions remains unclear. Here, we aimed to: (i) identify candidate CRN encoding genes in P. parasitica genomes; (ii) evaluate the transcriptional expression of P PCRN (Phytophthora parasitica Crinkler candidate) during the P. parasitica interaction with Citrus sunki (high susceptible) and Poncirus trifoliata (resistant); and (iii) functionally characterize two PpCRNs in the model plant Nicotiana benthamiana.

Results: Our in silico analyses identified 80 putative PpCRN effectors in the genome of $P$. parasitica isolate 'IAC 01/ 95.1'. Transcriptional analysis revealed differential gene expression of $20 P p C R N$ candidates during the interaction with the susceptible Citrus sunki and the resistant Poncirus trifoliata. We have also found that P. parasitica is able to recognize different citrus hosts and accordingly modulates PpCRNs expression. Additionally, two PpCRN effectors, namely PpCRN7 and PpCRN20, were further characterized via transient gene expression in N. benthamiana leaves. The elicitin INF-1-induced Hypersensitivity Response (HR) was increased by an additive effect driven by PpCRN7 expression, whereas PPCRN2O expression suppressed HR response in $N$. benthamiana leaves. Despite contrasting functions related to HR, both effectors increased the susceptibility of plants to $P$. parasitica.
\end{abstract}

Conclusions: PpCRN7 and PpCRN20 have the ability to increase $P$. parasitica pathogenicity and may play important roles at different stages of infection. These PpCRN-associated mechanisms are now targets of biotechnological studies aiming to break pathogen's virulence and to promote plant resistance.

Keywords: Crinkler effectors, Hemibiotrophic, Oomycetes, Citrus, Hypersensitivity response, Virulence

\section{Background}

Plant-pathogen interactions are a ruthless battle, as the pathogens strive to invade host tissues in order to obtain nutrients and complete their life cycle. On the other hand, plants attempt to restrict the pathogen invasion and colonization to ensure its own survival. Frequently, the pathogen's attack strategy relies on the secretion of effector proteins that functionally modulate the interaction with the host plant at early times of infection and

\footnotetext{
* Correspondence: marcos@ccsm.br

${ }^{+}$Heros J. Máximo and Ronaldo J. D. Dalio contributed equally to this work.

'Biotechnology Laboratory, Centro de Citricultura Sylvio Moreira/Instituto

Agronômico (IAC), Cordeirópolis, SP, Brazil

Full list of author information is available at the end of the article
}

colonization [1-3]. Plants recognize conserved pathogenassociated molecular patterns (PAMPs) and trigger the pattern-triggered immunity (PTI) for defense. To break this immunity process, pathogens secrete their repertoire of effectors, promoting the effector-triggered susceptibility (ETS) in the plant $[4,5]$.

Phytophthora is a genus of oomycete that forms a group of eukaryotic microorganisms classified within Stramenopiles, which are notable plant pathogens, affecting a wide variety of plants, and causing an extensive damage in natural and cultivated ecosystems [6]. The most notorious oomycete belong to genus Phytophthora (meaning "plant destroyer" in Greek) that includes more than 100 species,

(c) The Author(s). 2019 Open Access This article is distributed under the terms of the Creative Commons Attribution 4.0 International License (http://creativecommons.org/licenses/by/4.0/), which permits unrestricted use, distribution, and reproduction in any medium, provided you give appropriate credit to the original author(s) and the source, provide a link to the Creative Commons license, and indicate if changes were made. The Creative Commons Public Domain Dedication waiver (http://creativecommons.org/publicdomain/zero/1.0/) applies to the data made available in this article, unless otherwise stated. 
arguably the most devastating pathogens of dicot plants [7]. Phytophthora spp. are hemibiotrophic pathogens [8] and several species of Phytophthora have already been described as causal agents of disease in Citrus, including the most important and widespread $P$. nicotiane $(=P$. parasitica) Dastur and P. citrophthora (Sm. \& Sm.) Leonian, [9]. However, that also includes $P$. boehmeriae Saw, $P$. cactorum (Lebert \& Cohn) Srhöter, P. capsici Leonian, P. cinnamomi Rands, $P$. ciricola Saw, $P$. drechsleri Tucker, $P$. hibernalis Meat, $P$. megasperma Drechsler, $P$. palmivora (Butler) Butler, P. nicotiane (= P. nicotiane B. De Haan var.). Phytophthora spp. can cause several diseases in citrus depending on the plant tissue that is infected, with root rot and trunk gummosis [10,11]. Citrus gummosis disease is considered one of the most serious diseases affecting citrus industry worldwide, causing significant economic losses in several regions [12].

Species belonging to the genus Phytophthora had their genome sequenced, revealing that this oomycete presents several putative effector protein-coding genes that can potentially manipulate the physiology of host plants. Such effectors can either promote virulence or activate the host defense system [13, 14]. Generally, effector proteins are classified, based on their location, as apoplastic (when secreted in the extracellular matrix) or cytoplasmic (when translocated into the host cells) [13, 15]. The cytoplasmic effectors, such as RxLR or Crinkler (CRN), are modular proteins that carry conserved domains in their $\mathrm{N}$-terminal portion $[2,13,16,17]$. These $\mathrm{N}$-terminal conserved domains are related to the translocation of the effector to the host cytoplasm and define the effectors superfamily. At the $\mathrm{C}$-terminal region, there are more diversified types of domains that are not related to protein translocation, but instead, to the specific functions of effectors [15].

The CRN proteins mostly share the N-terminal motifs LxLFLAK (leucine-any amino acid-phenylalanine-leucine-alanine-lysine) that is highly conserved [15]. The majority of the CRN effectors also carry a DWL domain and an HVLVXXP motif downstream the LxLFLAK motif [15]. These effector proteins are predominantly associated with necrosis induction; however; some of them may inhibit or suppress programmed cell death (PCD), triggered by PAMPs [18-20].

To investigate the role of $P$. parasitica PpCRN effector family during plant-pathogen interactions, this work presents: (i) identification of candidate $P p C R N$ genes in $P$. parasitica isolate 'IAC_01/95.1' and genome comparison with genome data available of other isolates; (ii) transcriptional gene analysis of candidate $P p C R N$ s expression during $P$. parasitica interaction with the susceptible Citrus sunki and the resistant Poncirus trifoliata; and (iii) functional characterization of two $P p C R N \mathrm{~s}$ in $P$. parasitica interaction with the model plant Nicotiana benthamiana.

\section{Results}

Candidate Crinkler (CRN) effectors of $P$. parasitica (PpCRN) Here, we explored the available genomes of $P$. parasitica deposited under the international project "Phytophthora parasitica genome initiative" database (https://www.ncbi.nlm.nih. gov/assembly/?term=phytophthora\%20parasitica) to obtain the genome data of $P$. parasitica isolates from different hosts and geographic origins, to study the CRN effectors.

We identified 80 candidate genes encoding PpCRN effector proteins in the genome of $P$. parasitica isolate 'IAC_01/95.1' (Fig. 1). Similarly, candidate PpCRN effectors were found in the genomes of other P. parasitica isolates, with the isolate 'P10297' showing the highest number of $P p C R N$ candidates (106), and the isolate 'CHvinca01' the least number (78). The conserved LxLFLAK motif was identified in several PpCRN candidates from distinct $P$. parasitica genomes, but it showed a variation in terms of quantity and sequence diversity from one genome to another (Fig. 1). Secretory signal peptides were predicted in only six PpCRN candidates, namely PpCRN2, PpCRN5, PpCRN7, PpCRN10, PpCRN14 and PpCRN20, which corresponds to $7.5 \%$ of total candidate proteins identified in the genome of isolate 'IAC 01/95.1'.

The genome architecture can provide information about the function, regulation and adaptation of genes [15]. In Phytophthora species, some regions are rich in replicate and sparse genes, which are related to pathogenicity, including effector-coding genes. The $P$. parasitica genome shows a heterogeneous distribution according to the size of the intergenic regions. The genome architecture of the $P$. parasitica isolate IAC 01_95 is shown in Fig. 2. The flanking distance (intergenic region) between neighbouring genes provides a measurement of the local distribution of gene density, which can be plotted into two-dimensional graph based on the length of intergenic regions between neighbouring genes, at their $5^{\prime}$ - and 3 '-end. The genome architecture of $P$. parasitica shows that 20 selected $C R N$ genes are located at the sparse region of the genome (Fig. 2). In the sparse region, due to its plasticity, the chances of emerging a new effector or simply evolving an already existing protein is more likely to happen than in the dense region.

In order to verify the similarity between the identified putative PpCRN protein sequences and previously described CRNs, a Neighbour-Joining tree was predicted using all identified PpCRNs and CRN sequences from the Uniprot database (Fig. 3a). The wide distribution of PpCRN sequences over the tree shows a great sequence divergence between them. This distribution pattern was also followed by the $P$. infestans sequences used in the tree. In order to address this high divergence between PpCRN sequences, we searched for common motifs between them. Twentytwo motifs were predicted as present in at least three of the total sequences (Fig. 3b). The identification of distinct CRN motifs was named from M1 to M22 (Fig. 3b). Sequences 


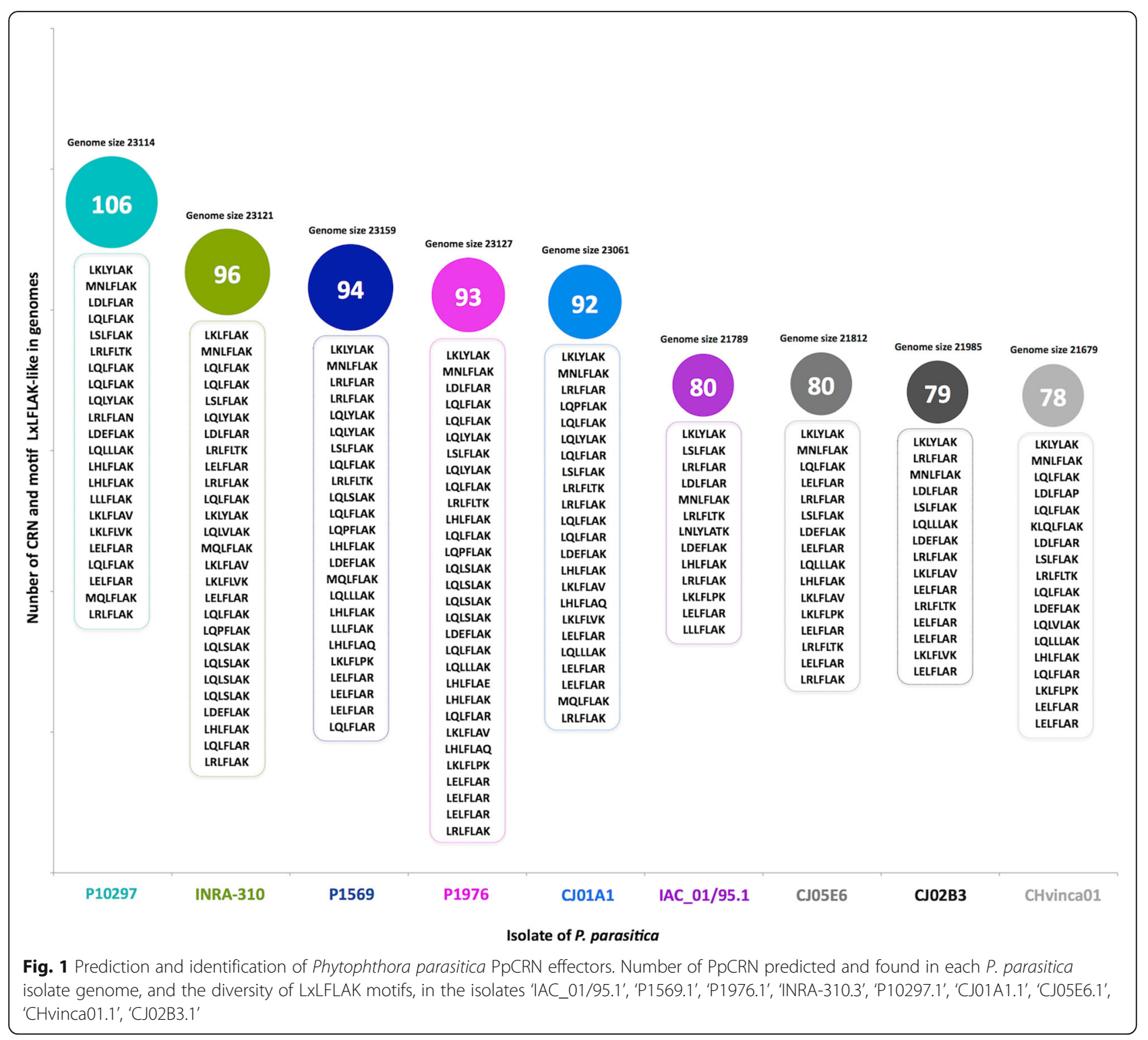

and additional information of the 80 PpCRN candidates are shown in the Additional file 1.

All 80 predicted $P p C R N$ s from the isolate 'IAC_01/ 95.1' genome were used as query for searching homologous genes within other eight genomes from different isolates of $P$. parasitica, which are named 'P1569.1', 'P1976.1', 'INRA-310.3', 'P10297.1', 'CJ01A1.1', 'CJ05E6.1', 'CHvinca01','CJ02B3.1' (Fig. 4). We have found similar PpCRNs in the genomes of other P. parasitica isolates by applying a Blastp search using the 80 PpCRN candidates protein sequences of the 'IAC_01/ 95.1' genome as query. This genomic approach revealed the distribution and proximity of genomes to the eighty PpCRNs of the 'IAC_01/95.1' isolate. Similar sequences to $P p C R N 7$ and $P p C R N 20$ were found in all nine $P$. parasitica genomes (Additional file 3: Fig. S1), whereas $P p C R N 4$ and PpCRN40 are unique to the 'IAC_01/95.1' genome (Fig. 4a). Based on the 80 candidate $P p C R N s$, our analyses revealed that the closest genome to $P$. parasitica isolate 'IAC_01/95.1' is the isolates 'P1569.1' and 'CJ05E6' from citrus and tobacco (Fig. 4a). Most of the $P p C R N$ candidates predicted in the isolate 'IAC_01/95.1' were also found in the other isolates, varying from 64 out of 80 candidates in the citrus isolate 'P1569.1' to 56 out of 80 candidates in the tobacco isolate 'INRA-310.3' (Fig. 4b). 35 predicted PpCRNs (43.75\%) from isolate 'IAC_01/95.1' are also found in all other eight isolates, with at least one corresponding protein found in each $P$. parasitica isolate genome, presenting more than 95\% identity and 50\% coverage (Fig. 4c). 


\section{Phytophthora parasitica 01/95.1 genome}

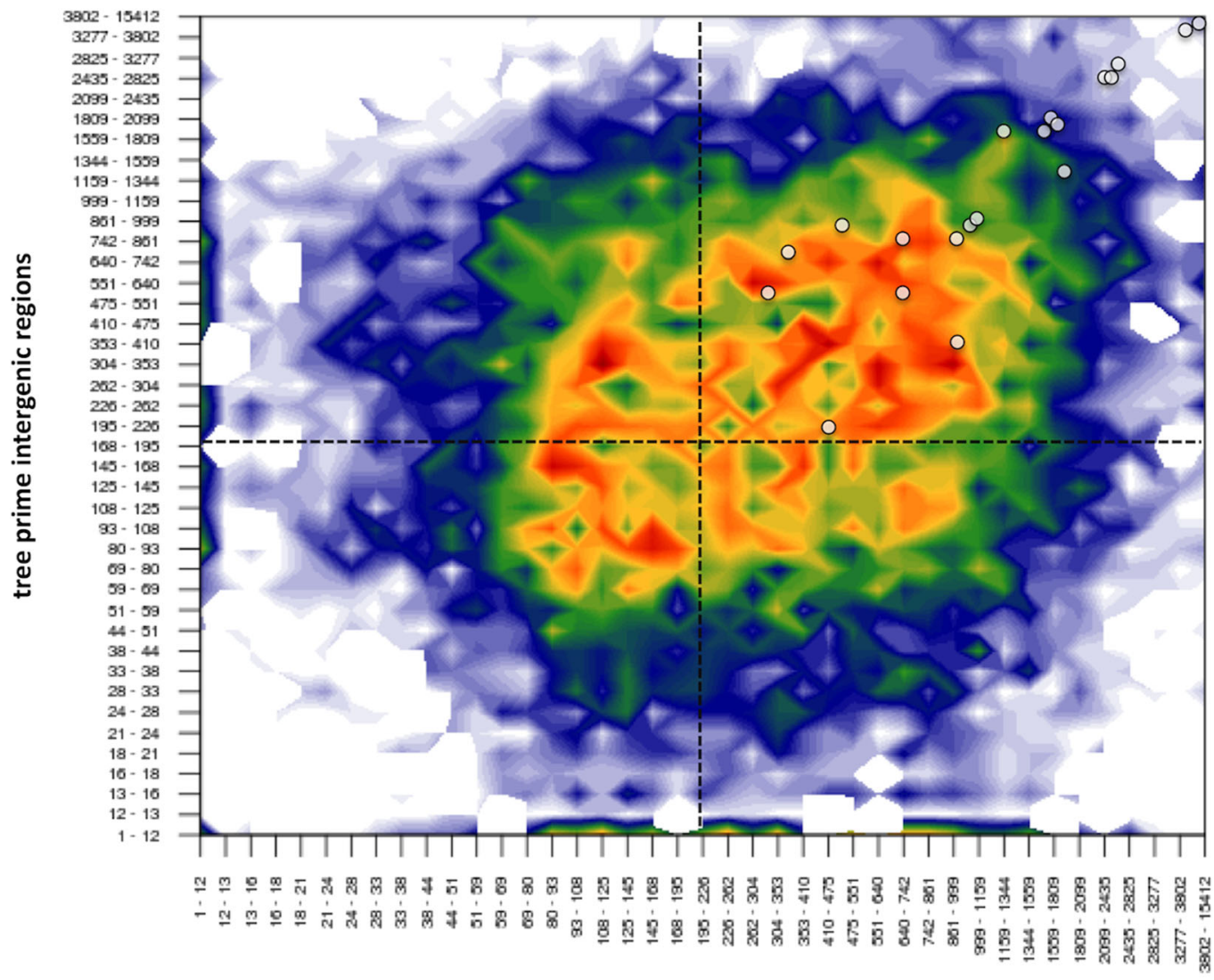

Number of genes

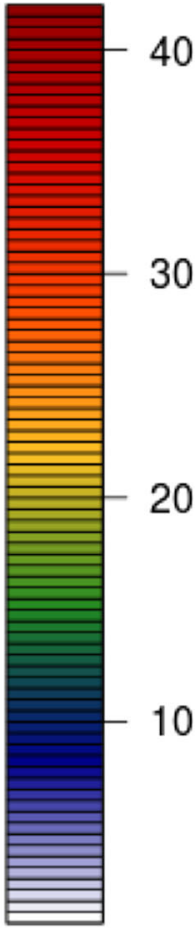

five prime intergenic regions

Fig. 2 Genome architecture of P. parasitica isolate 'IAC_01/95.1' containing 20 candidate PpCRN effectors. All PpCRNs are localized at the sparse region of the genome. The heat map shows the number of genes at the same spot on the chart

Predicted PpCRNs are transcriptionally deregulated during Citrus-P. parasitica interaction

Twenty $P p C R N$ candidates were selected for gene expression analysis during the plant-pathogen interaction between P. parasitica and two Citrus species (C. sunki and P. trifoliata). We chose these two citrus species because they have contrasting response to Phytophthora parasitica infection; Citrus sunki is susceptible and Poncirus trifoliata is resistant to this pathogen. These candidates, PpCRN1 to PpCRN20, were selected based on the presence of one or more of the following features: (i) presence of a secretion signal peptide; (ii) absence of transmembrane domains; (iii) differential gene expression in other plant-pathogen interaction studies; (iv) presence of conserved CRN domain; (v) nuclear or subcellular localization signals; (vi) sequence homology with effectors from other species; (vii) $P p C R N$ gene located at the sparse regions of the genome.

Gene expression analysis revealed an expressional dynamics of $P p C R N$ effectors during the interaction of $P$. parasitica with the citrus plants. Our analysis showed that these $P p C R N$ family members had their transcriptional levels altered, according to the citrus species and infective stage $[11,21]$ (Figs. 5, 6 and Additional file 4: Figure S2). Figure 5 shows that, in P. trifoliata, the vast majority of $P p C R N s$ candidate genes were up-regulated along the time points, except for $P p C R N 1, P p C R N 7$ and PpCRN10 that were suppressed, at least in one time-point. $P p C R N 4$, which is unique to the isolate 'IAC 01/95.1' genome, had the highest differential expression level detected among the $P p C R N$ candidates, followed by $P p C R N 16$ and $P p C R N 18$, both exhibiting high levels of transcripts. The candidates $P p C R N 9, P p C R N 11$ and $P p C R N 12$, showed constant expression levels throughout the time points analysed. In addition, $P p C R N 7$ expression were initially suppressed at $3 \mathrm{~h}$ post inoculation (hpi) and then returned steadily to basal levels at the $6 \mathrm{~h}$ time-point onwards, whereas PpCRN20 were slightly induced 6 dpi onwards (Fig. 5).

In $C$. sunki, most of $P p C R N s$ were transcriptionally induced (Fig. 6). However, PpCRN4, PpCRN9 and PpCRN12 transcripts were down-regulated at all time-points. $P p C R N 8$ and $P p C R N 13$ expression showed partial suppression in 
A

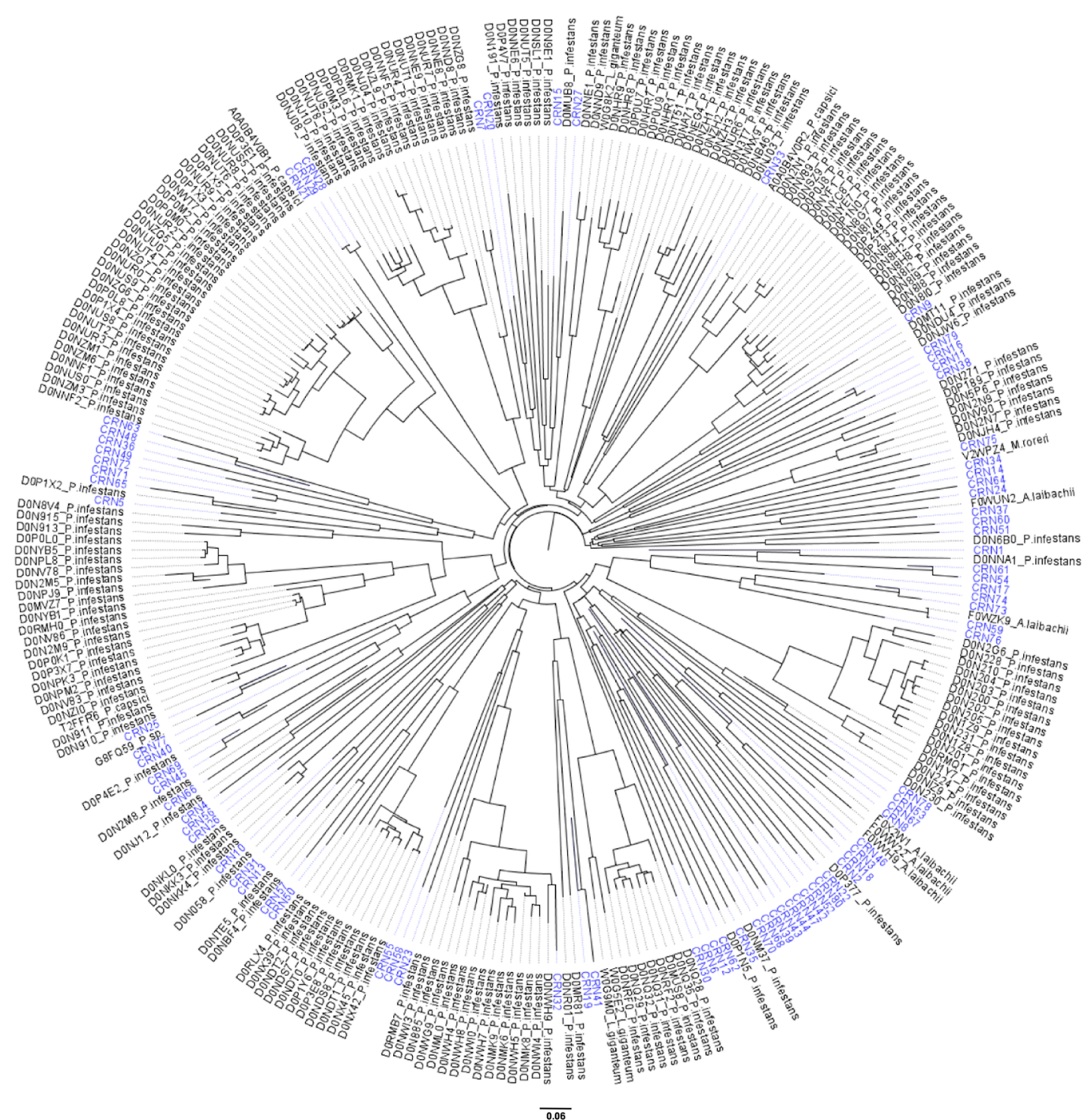

B

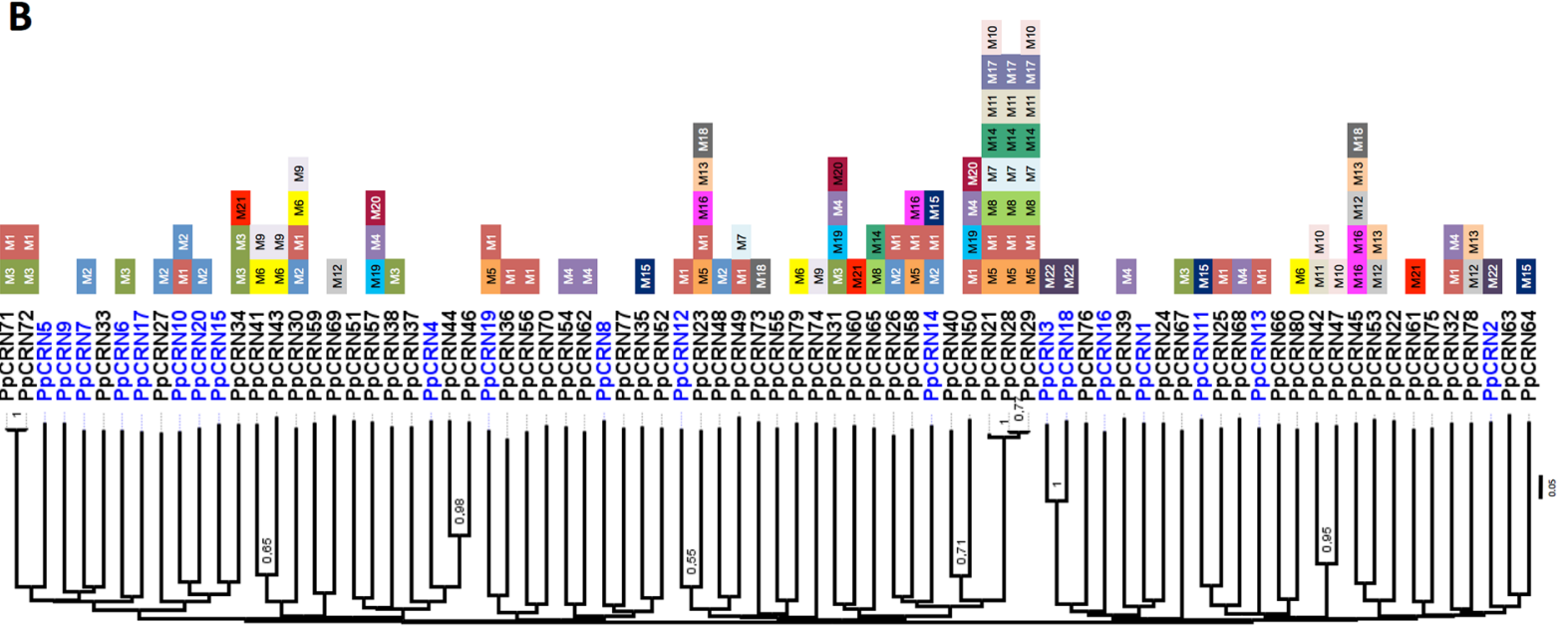

Fig. 3 (See legend on next page.) 
(See figure on previous page.)

Fig. 3 Phylogenetic analysis of predicted PpCRN from P. parasitica isolate 'IAC_01/95.1'. a Sequences from P. parasitica isolate 'IAC_01/95.1' are shown in in blue, and sequences from other oomycetes identified in the Uniprot database are shown in black. Clusters were obtained according to the Neighbor-Joining method. Sequences obtained in the Uniprot are designated by their respective access number in the database and by species name. $\mathbf{b}$ Clustering based on the similarity of CRN motifs. In blue are shown the 20 PpCRNs selected for gene expression analysis. The variation of CRN motif are indicated by colored boxes named from M1 to M22

most of the time-points; at $96 \mathrm{hpi}$, an increase in their transcriptional levels were detected. Contrastingly, $P p C R N 7$ and $P p C R N 20$ expression were induced throughout the development of the disease, with $P p C R N 7$ showing the highest differential expressional level among all $P p C R N$ candidates (Fig. 6). Recently our group published data showing that $P$. parasitica has the ability to recognize and regulate gene expression levels of effectors CRN, RxLR, Elicitin, CBEL and $N P P-1$ over time and as a function of interaction with $C$. sunki and $P$. trifoliata [11].
Functional characterization of the PpCRN7 and PpCRN20

Functional genomics were further taken to explore the potential role of two candidate PpCRN effectors, which are supposed to modulate cellular and molecular responses in host plants. Our in silico analyses identified that the candidate effectors $P p C R N 7$ and $P p C R N 20$ would be good candidates for characterization, as both showed: (i) secretory peptide signals; (ii) absence of transmembrane domains; (iii) genome location at the sparse regions; (iv) presence in all genomes of $P$. parasitica isolates herein analyzed, with

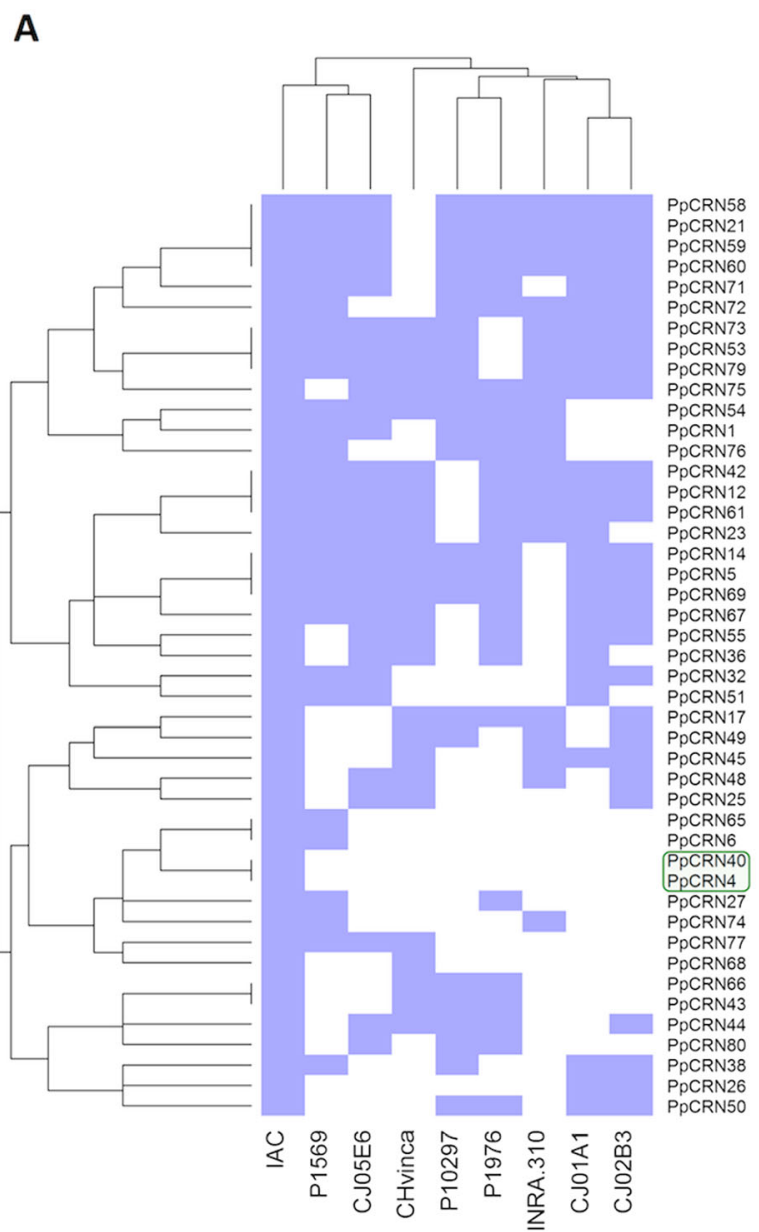

B

80

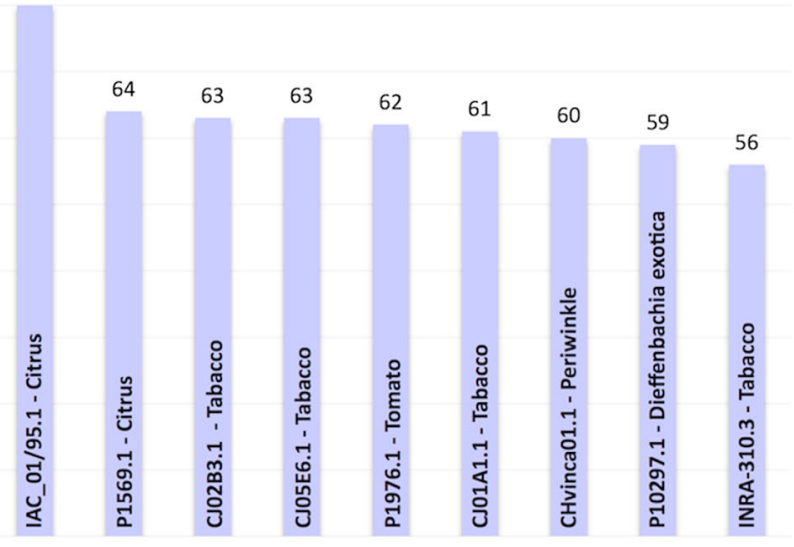

\section{C}

PpCRN2

PpCRN3

PpCRN7

PpCRN8

PDCRN9

PpCRN10

PpCRN11

\section{PpCRN13}

PpCRN15

PpCRN16

PpCRN18

PpCRN19

PpCRN20

PpCRN22
PpCRN24 PpCRN35
PpCRN28 PpCRN37
PpCRN29 PDCRN39
PpCRN30 PpCRN41
PpCRN31 PpCRN46
PpCRN33 PpCRN47
PpCRN34 PpCRN52

PpCRN56

PpCRN57

PpCRN62

PpCRN63

PpCRN64

PpCRN70

PpCRN78

Fig. 4 Genomic analysis of PpCRNs from diferent isolates of $P$. parasitica. a Dendogram of the distance between eight $P$. parasitica genomes, from isolates 'P1569.1', 'P1976.1', 'INRA-310.3', 'P10297.1', 'CJ01A1.1', 'CJ05E6.1', 'CHvinca01.1', 'CJ02B3.1', in relation to the 'IAC_01/95.1' genome. The green box marks PpCRN4 and PpCRN40 that are unique to the 'IAC_01/95.1' genome. $\mathbf{b}$ The 80 PpCRNs predicted in the isolate 'IAC_01/95.1' and the corresponding presence in the other eight genomes. $\mathbf{c}$ ldentification of 35 predicted PpCRN that are found in all nine $P$. parasitica genomes. PpCRN7 and PpCRN20, which were further characterized, are highlighted in red 

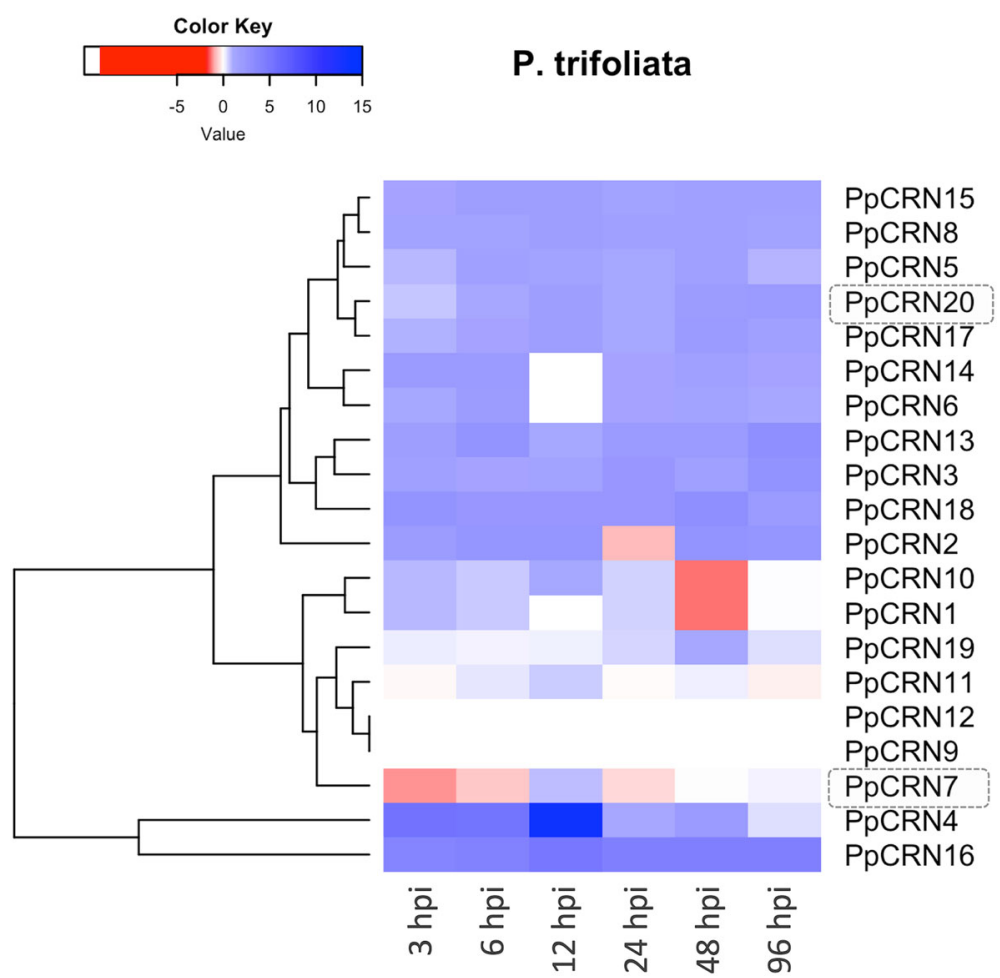

Fig. $5 P p C R N$ gene expression analysis during P. parasitica interaction with $P$. trifoliata. Heat map shows gene expression levels of 20 predicted $P p C R N$ effectors in $P$. trifoliata infected samples collected at $3,6,12,24,48$, and $96 \mathrm{~h}$ post $P$. parasitica inoculation (hpi). The data are presented as expression relative to the reference genes S3A and UBC. The values of gene expression are plotted in Log2. Up-regulating genes are indicated by the color red $>1.0$ $-\geq 15.0)$ and down-regulating genes by the red color $(<1.0-\leq-15.0)$. PpCRN7 and PpCRN20, which were further characterized, are highlighted in grey

a high degree of sequence identity; and (v) presence of known conserved CRN domains (Additional file 3: Figure S1 and Additional file 1).

Therefore, to reveal the functional role of $P p C R N 7$ and $P p C R N 20$, a transient expression assay was carried out via agrotransformation in $N$. benthamiana leaves. The insertion of PpCRN7 and PpCRN20 transgenes in the plantexpressing vector pCambia1302 (Additional file 5: Figure S3A) was confirmed by gel eletroforesis after enzymatic digestion. The nucleotide fragments corresponds to the expected size of PpCRN7 (430 pb) and PpCRN20 (439 pb) (Additional file 5: Figure S3B). Furthermore, the expression of the proteins PpCRN7 and PpCRN20 in plant was confirmed by Western blotting (Additional file 5: Figure $\mathrm{S} 3 \mathrm{C}$ ). These constructs were then used to evaluate the effect of PpCRN7 and PpCRN2O to induce or supress HR in $N$. benthamiana leaves by co-expressing them along with the elicitin INF-1 - a known cell death induction factor $[22,23]$. The elicitin INF-1 is well known to induce HR in Nicotianae species. Therefore, it is commonly used in functional characterization studies of effectors [23].

\section{PpCRN7 enhances INF-1-induced HR response}

To test the effect of $P p C R N 7$ expression towards the HR mediated by the elicitin INF-1, we performed agrotransformation of plant expressing vectors containing (i) empty vector, (ii) $P p C R N 7$, (iii) $I N F-1$, and (iv) co-expression of $P p C R N 7+I N F-1$ (Fig. 7a). No symptoms were observed in leaves infiltrated with the empty vector or PpCRN7-containing vector alone. However, INF-1-expressing leaves showed HR response, with evident tissue necrosis in the agroinfiltrated area, as also observed in leaves co-infiltrated with $P p C R N 7$ along with $I N F-1$ (Fig. 7a). Therefore, transient expression of $P p C R N 7+$ INF-1 in $N$. benthamiana leaves revealed a synergistic activity of the CRN effector with the elicitin, as the HR response was intensified, leading to an anticipated and more prominent occurrence of PCD.

To verify if PpCRN7 effector also affects the release of reactive oxygen species (ROS) and oxidative burst, a biochemical and colorimetric assay was performed on $N$. benthamiana agroinfiltrated leaves (Fig. 7b). In this assay, the substrate DAB (3,3'-diaminobenzidine) is oxidized by hydrogen peroxide, to generate a dark brown precipitate, which allows the visual detection - the darker the tissue, the more ROS released. The INF-1-expressing area appears greatly dark, indicating that ROS were produced by still-living cells, whereas in the area co-infiltrated INF-1 with PpCRN7 showed mild dark staining, compared to the area expressing INF-1 only 

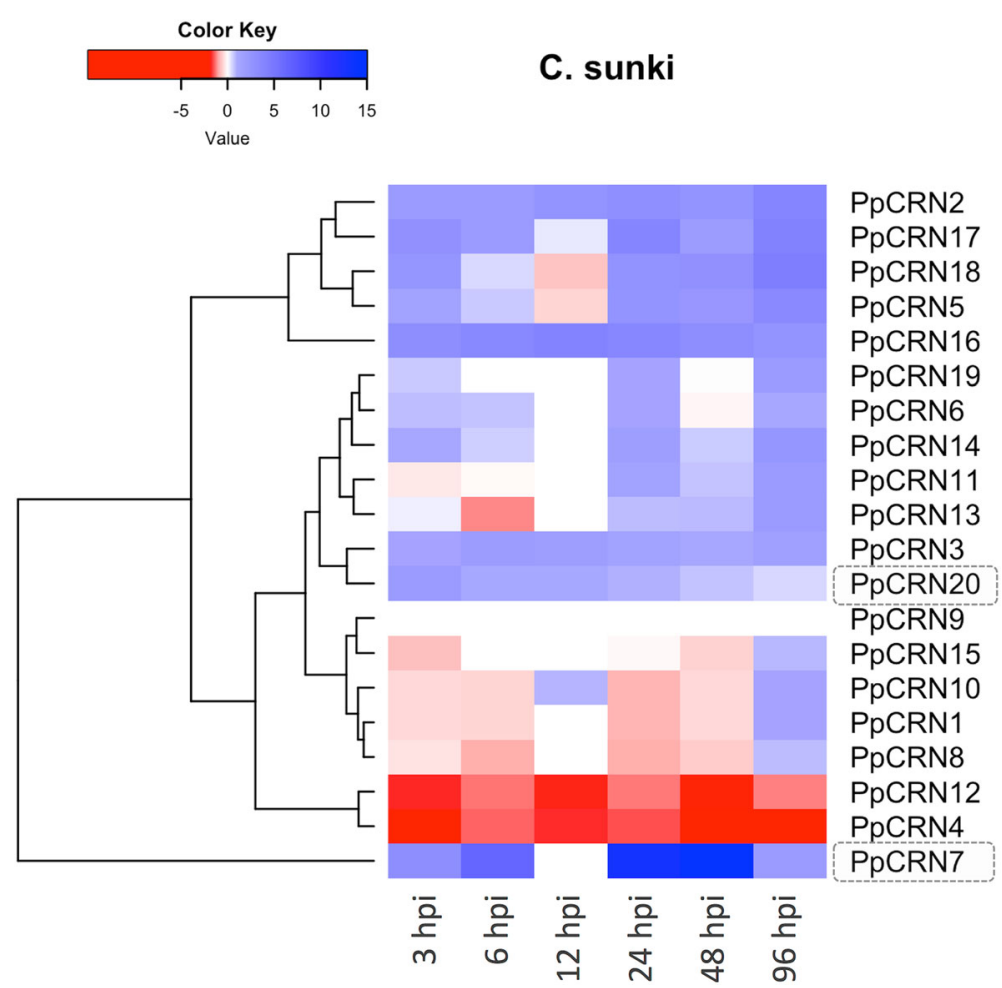

Fig. 6 P PCRN gene expression analysis during P. parasitica interaction with C. sunki. Heat map shows gene expression levels of 20 predicted PpCRN effectors in C. sunki infected samples collected at 3, 6, 12, 24, 48, and $96 \mathrm{~h}$ post P. parasitica inoculation (hpi). The data are presented as expression relative to the reference genes S3A and UBC. The values of gene expression are plotted in Log2. Up-regulating genes are indicated by the color red (> $1.0-\geq 15.0)$ and down-regulating genes by the red color $(<1.0-\leq-15.0)$. PpCRN7 and PpCRN20, which were further characterized, are highlighted in grey

A

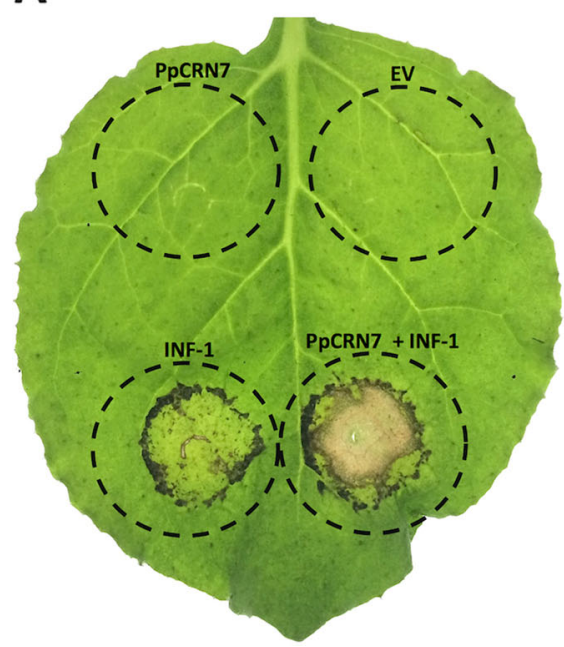

B

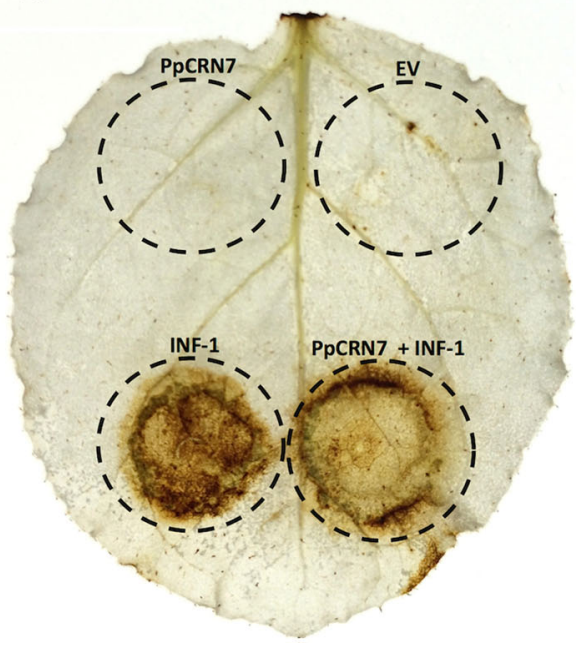

Fig. 7 Transient expression of PpCRN7 in N. benthamiana leaves. a N. benthamiana leaf agroinfiltrated with empty vector (EV), PpCRN7-containing vector, INF-1-containig vector, and PpCRN7- + INF-1-containing vectors. b DAB assay on N. benthamiana, as indicated in A, agroinfiltrated indicates $\mathrm{H}_{2} \mathrm{O}_{2}$ accumulation (brownish colour). Dots in circle represents the agroinfiltrated area 
(Fig. 7b). It suggests that cells in this area are already dead, due to the anticipation and amplification of ROS release and subsequent $\mathrm{HR}$, driven by the synergistic activity of the effector PpCRN7 along with INF-1. Very likely, the biochemical target of the PpCRN7 effector is present down-stream the activation of ROS-release by INF-1, since, when alone, without INF-1, the PpCRN7 effector has no activity regarding release of ROS or induced PCD.

Additionally, we tested if the A. tumefaciens concentration, for the transient expression assay would be related to the observed HR amplification (Additional file 6: Figure S4). Agronfiltration solution were adjusted to an OD600 of 0.5 and 1.0 and used to co-infiltrate $P p C R N 7$ along with $I N F-1$, and empty vector (EV) along with INF-1. The results were similar as $P p C R N 7$ enhanced INF-1-induced HR response, independent of $A$. tumefaciens concentration, confirming that PpCRN7 acts synergistically with INF-1 in the manipulation of plant defence mechanisms, which results in oxidative burst, programmed cell death and tissue necrosis (Additional file 6: Fig. 4).

\section{PpCRN20 suppresses INF-1-induced HR response}

The same approach was carried out to test the effect of PpCRN20 expression towards the HR mediated by INF1 . We performed agroitransformation of plant expressing vectors containing (i) empty vector, (ii) $P p C R N 20$, (iii) $I N F-1$, and (iv) $P p C R N 20+I N F-1$. No symptoms were observed in leaves infiltrated with the empty vector or PpCRN20-containing vector alone (Fig. 8a). However, as expected INF-1-expressing leaves showed HR response, with evident tissue necrosis in the area that was agroinfiltrated (Fig. 8b). The co-infiltration of INF-1 along with $P p C R N 2 O$ presented a strong reduction on INF-1-induced symptoms. This result suggests that PpCRN20 acts as a suppressor of INF-1-induced HR response (Fig. 8b).

The DAB assay on $N$. benthamiana leaves showed no ROS production when expressing either an empty vector or PpCRN20-containing vector (Fig. 8c). However, leaves co-expressing PpCRN2O along with INF-1 showed a significant decrease in ROS production when compared to INF1-expressing site (Fig. 8d). The absence of tissue necrosis and decrease on ROS production indicates that PpCRN20 may act as HR suppressor.

\section{Transient expression of $P p C R N 7$ and PpCRN20 increases $N$.} benthamiana susceptibility

To understand the biological role mediated by PpCRN7 and PpCRN20 during the process of $P$. parasitica infection, $N$. benthamiana leaves were inoculated with zoospores of $P$. parasitica, $24 \mathrm{~h}$ after agrotransformation with $P p C R N 7$ - or $P p C R N 20$-containing vectors. Leaves, transiently expressing PpCRN7 and PpCRN20, inoculated with $P$. parasitica zoospores developed symptoms, measured at 72 and $144 \mathrm{~h}$ post inoculation (hpi), including severe wilt and tissue necrosis. Whereas $P$. parasitica-inoculated leaves, without $P p C R N$ expression, showed symptoms only at 144 hpi (Fig. 9a). No symptoms were observed on leaves without $P$. parasitica inoculation expressing either an empty vector or any $\operatorname{PpCRN~(Fig.~9a).~}$

P. parasitica genomic DNA from leaf tissues was quantified by RT-qPCR for samples collected at $72 \mathrm{hpi}$, to verify the growth rate and colonization of the oomycete, an indicative of $N$. benthamiana susceptibility (Fig. 9b). Significant differences were detected in $P$. parasitica-inoculated plants previously infiltrated with any $P p C R N-$ expressing vectors, and only inoculated plants (Fig. 9c). Higher amount of $P$. parasitica genomic DNA was found in leaves expressing $P p C R N 7$ and $P p C R N 20$ compared to leaves without $P p C R N$ expression (Fig. 9b,c). Significant differences were detected in transformed and subsequently inoculated samples, when compared to only inoculated plants at 72 hpi. Leaves expressing PpCRN20 presented the highest significant amount of $P$. parasitica genomic DNA, followed by leaves expressing PpCRN7.

\section{Discussion}

Plant-pathogen interaction involves a complex and intricate network of attack versus defense strategies. The pathogen aims to invade the host cells to obtain nutrients and complete its life cycle. On the other hand, the plant uses defense systems to contain the infection and ensure its own survival. The attack strategy of Phytophthora species relies on the secretion of effectors, in particular CRN effectors that modulate the interaction with the host plant defences and enable the infection and colonization processes $[18,19]$. Although CRN effectors are predominantly associated with the appearance of necrosis, there are a number of CRN effectors that can inhibit cell death, triggered by PAMPs [18].

In natural populations, changes in the frequency of effectors, driven by the resistance structure of the host population, are complemented by genetic drift, which may generate marked differences as a consequence of the survival or extinction of individual pathogen strains in a given geographical condition or space [24, 25]. On the other hand, gene flow or migration of pathogen populations may lead to the establishment of new populations or the introduction of new virulence combinations in existing populations [26]. The number of candidate $P p C R N$ effector genes predicted was different in each genome of $P$. parasitica isolates, as well as the LxLFLAK-like motifs varied among the isolates $[15,18]$. However, 35 predicted $P p C R N$-encoding genes were found conserved among all nine isolates. We believe that the PpCRN effectors might be important for P. parasitica pathogenicity during plant-pathogen interaction 


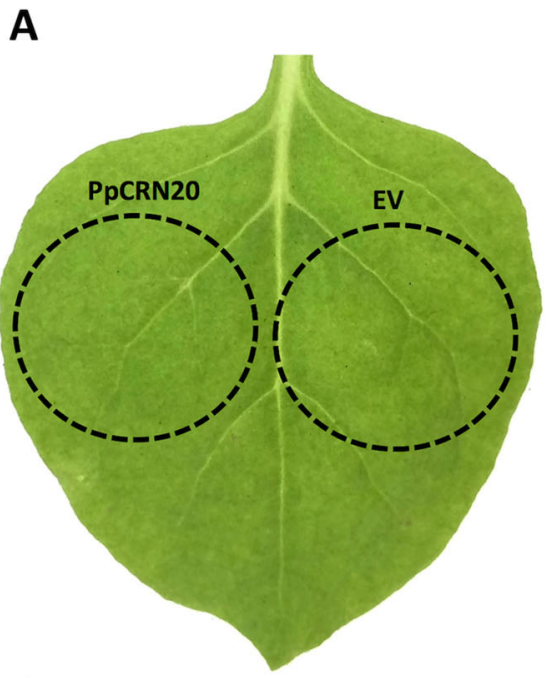

C

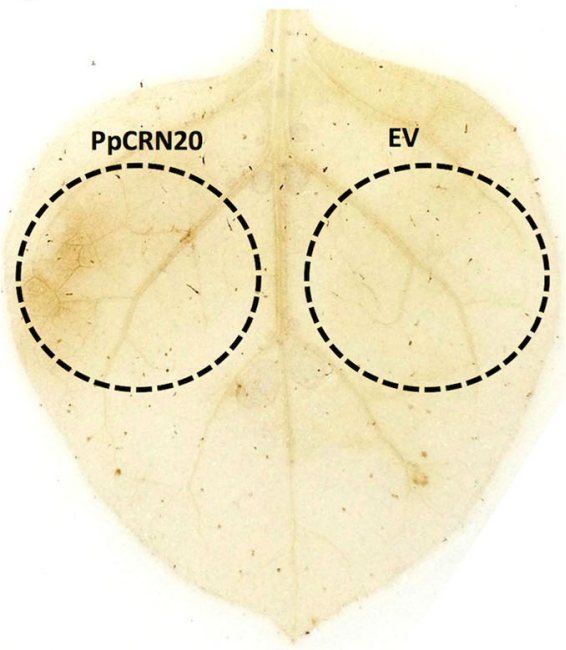

B

D
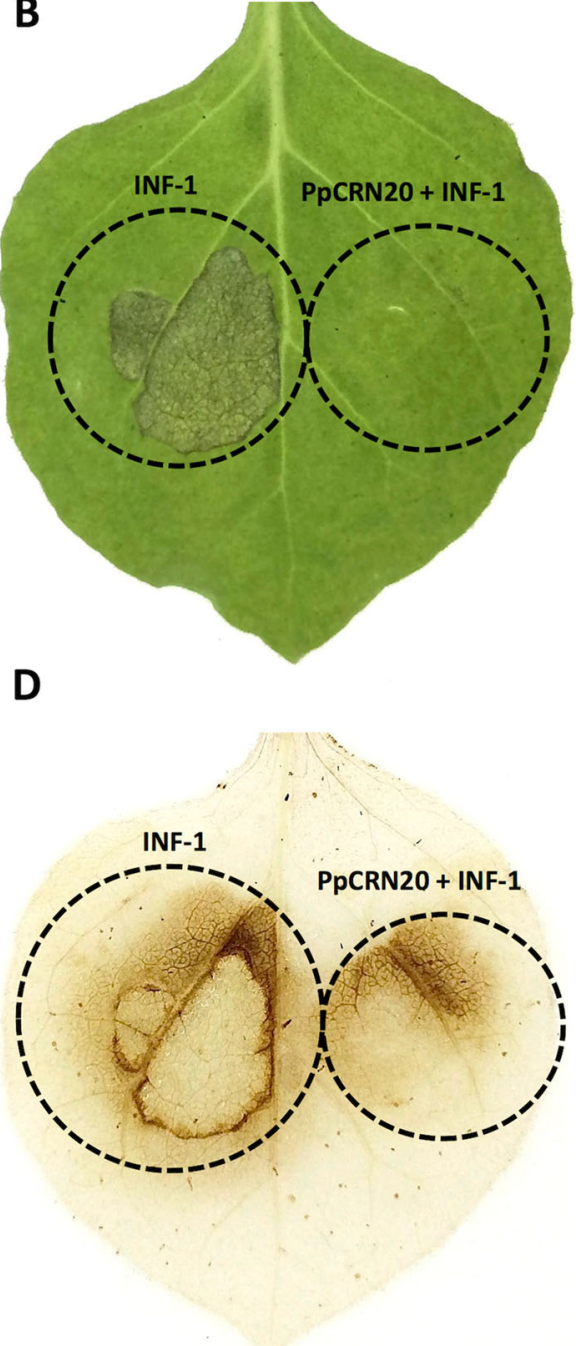

Fig. 8 Transient expression of PPCRN2O in N. benthamiana leaves. a N. benthamiana leaf agroinfiltrated with empty vector (EV) and PpCRN20containing vector. $\mathbf{b} \mathrm{N}$. benthamiana leaf agroinfiltrated with INF-1-containig vector, and PPCRN7- + INF-1-containing vectors. c DAB assay on N. benthamiana, agroinfiltrated as indicated in $\mathrm{A}$, indicates $\mathrm{H}_{2} \mathrm{O}_{2}$ accumulation (brownish colour). (d) DAB assay on N. benthamiana, agroinfiltrated as indicated in $\mathrm{B}$, indicates $\mathrm{H}_{2} \mathrm{O}_{2}$ accumulation (brownish colour). Dots in circle represents the agroinfiltrated area

considering the complexity and diversity of these effectors in $P$. parasitica isolates and their corresponding ecosystems. On the other hand, the predicted PpCRN4 and $P p C R N 40$ genes that were exclusively found in the genome of the isolate 'IAC01/95.1' might potentially represent an adaptation to the ecosystem that it was originated.

Based on the 80 predicted $P p C R N s$, the isolates 'IAC_ 01/95.1' and 'P1569' were the closest related P. parasitica isolates. Both of them were isolated from citrus plants. The lower genetic variability of these two isolates may be related to an adaptation to infect the same host. Additionally, this genome proximity could be also related to geographical factors, considering that the three closest related isolates ('IAC_01/95.1', 'P1569' and
'CJ05E6') belong to the same American continent and probably evolved from the same ancestor.

The protein primary structure of 80 CRN effector candidates from $P$. parasitica was identified in silico and presented distinct motifs of LxLFLAK. This complexity and diversity can be attributed to the hemibiotrophic lifestyle of $P$. parasitica, as well as the adaptive and coevolutionary forces that emerge from the great variety of host plants, which represents more than 250 genera [27]. This diversity found in PpCRNs primary structure can be, therefore, explained by the fact that effector molecules are modular, and likely to undergo changes in their sequences under selective pressure. These changes in gene sequence may inactivate the effector protein or rather provide a new function, increasing the pathogen 


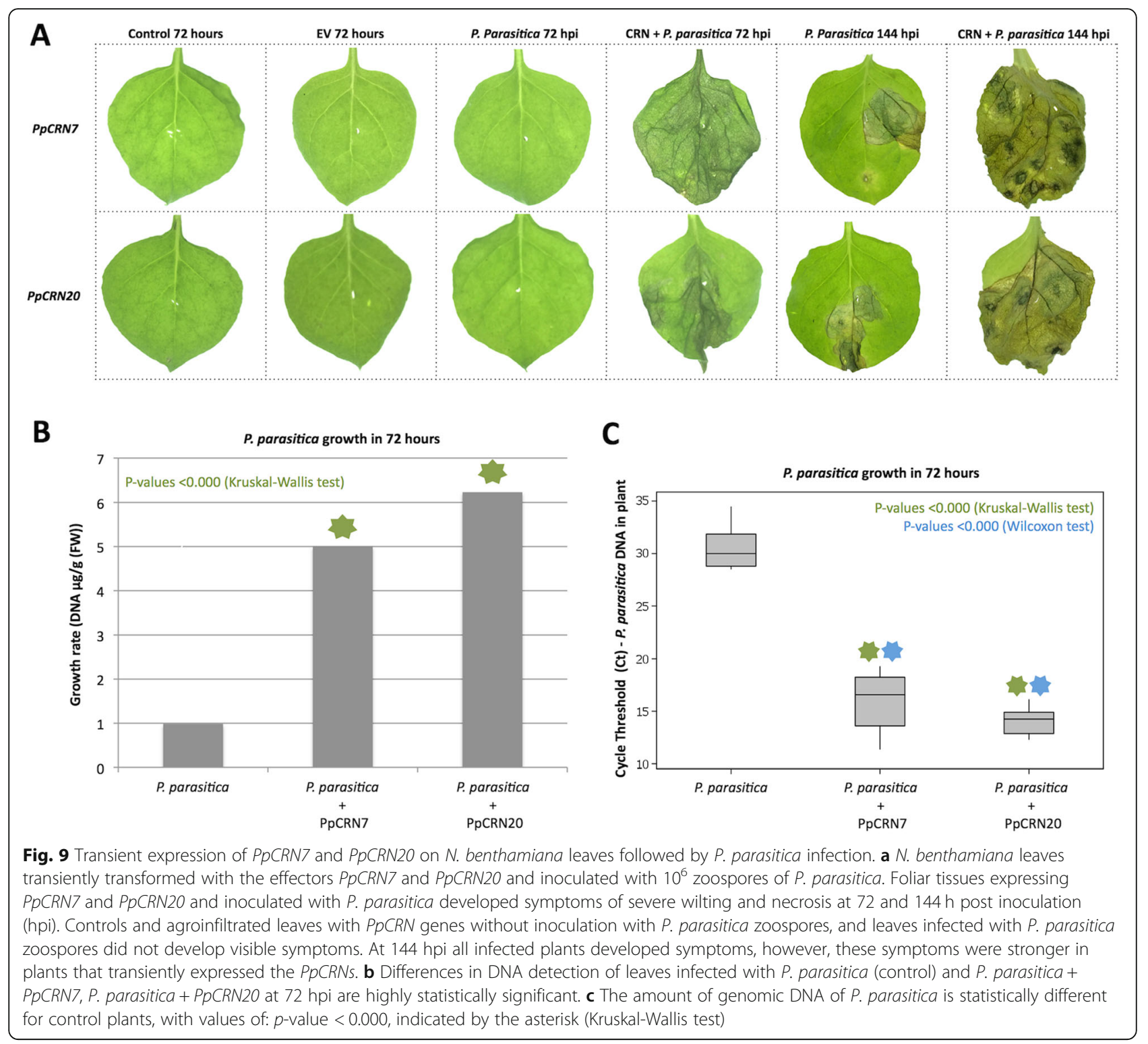

adaptation to environmental challenges (Haas et al., 2009). The diversity of $\mathrm{N}$-terminal and C-terminal portions of PpCRN sequences is consistent with results reported for a range of microorganisms, including Rhizophagus irregularis, P. capsici, Batrachochytrium dendrobatidis, Albugo laibachi, A. cândida, Pythium ultimum, Hyaloperonospora arabidopsidis, P. infestans, Aphanomyces euteiches, P. sojae, P. ramorum [15, 16, 28-35].

$P p C R N 7$ and $P p C R N 20$ are found in all $P$. parasitica isolates herein investigated, with a high degree of protein sequence conservation and located at the sparse regions, suggesting that both effectors may play a crucial role in the interaction of $P$. parasitica and host plants, likely modulating plant defence mechanisms. These two effector proteins have typical CRN motifs, the LxLFLAKlike motif, "LYLATK" in PpCRN7 and the "LFLAK" in
PpCRN20, as observed in different species of Phytophthora spp. [15, 29], followed by "DI" and "DWL" motifs at the N-terminal region.

In silico analysis and further functional characterization assays unveil the biological role of the two CRN effectors from $P$. parasitica. To investigate the role of these two PpCRNs effectors, a functional genomic and proteomic study was performed to explore the information obtained from $P$. parasitica genomes, and to evaluate the modulation of $N$. benthamiana defence responses, based on activation or suppression of HR response. PpCRN7 effector shows synergy with $P$. infestans elicitin INF-1 by anticipating and amplifying $\mathrm{HR}$ and $\mathrm{PCD}$ in $N$. benthamiana agroinfiltrated leaves. This effector-induced cell death promoted susceptibility, and similar results have already been reported for PiCRN8 and PsCRN63, effector proteins from 
P. infestans and P. sojae, respectively [36, 37]. The activity of the effector PsCRN63 is linked to disruption of the plant ROS homeostasis, by directly interacting with host catalases [38]. Our results suggest that the PpCRN7 effector is targeting/regulating a compound that is present down-stream the activation of ROS-release, however the exact nature of this target still remains to be elucidated. In a trophic point of view, it makes sense for $P$. parasitica to have/deploy an effector that can intensify the HR responses only after there was some PAMP or effector recognition, followed by defense activation by the host. That will result in a greater necrotic area that will benefit the necrotrophic stage of the pathogen. A strong HR response may fail to kill hemibiotrophic pathogens such as $P$. parasitica, as these can feed on dead tissue. It has been reported [11] that a strong defense response of Citrus sunki infected with $P$. parasitica led to the activation of a vigorous HR that was not sufficient to kill the pathogen, but rather increased its colonization [11].

Multiple effectors might act in the same pathways and only the most efficient effector might prevail and manifest the disease symptoms. PpCRN7 has an additive effect on INF-1 function, enhancing HR.

Conversely, PpCRN20 effector suppresses HR response, which resulted in a decrease of ROS accumulation in agroinfiltrated $N$. benthamiana leaves. Hence, it suggests that PpCRN20 might be an important effector used by $P$. parasitica to combat the plant defences. Several CRN effectors have been shown to suppress elicitor-triggered plant cell death $[39,40]$. For instance, $P$. sojae PsCRN70 and PsCRN115 suppress PCD by, decreasing $\mathrm{H}_{2} \mathrm{O}_{2}$ accumulation and down-regulating defense-associated genes, including PR1b, PR2b, ERF1 and LOX genes [19] and interacting with plant catalases to inhibit PCD via ROS accumulation [20]. Similarly, the $P$. parasitica RxLR effector, PpRxLR2, was able to completely inhibit the INF-1 induced cell death in $N$. benthamiana leaves [22].

$P$. parasitica is a hemibiotrophic pathogen and as such has the ability to feed on living or dead tissues. Several authors pointed that the hemibiotrophic lifestyle of $P$. parasitica can be obeserved in two temporal phases, an initial biotrophic one and later a necrotrophic phase [41-43]. Based on that, we propose the biological model of the interaction between $P$. parasitica and plant hosts, which includes the temporal and functional activity of PpCRN7 and PpCRN20 effectors.

Our hypothesis is that PpCRN20 acts in initial stages of infection, playing an important role by suppressing HR and PCD in plants, thus favoring the infection and colonization of plant living tissues. In this biotrophic phase, plant cells provide durable and renewable nutrients, the integrity of photosynthetic and metabolically active plant tissues would favor $P$. parasitica energetic fitness and cell cycle and will contribute to the colonization establishment. Later on infection, the plant physiological homeostasis might be already compromised, some individual cells or tissues may be damaged, leading to host recognition of damage-associated molecular patterns (DAMPs) and activation of defense responses, including $\mathrm{HR}$. The pathogen colonization process is completed with the activity of PpCRN7, that potentiate HR, and subsequently, PCD in plant tissues. This significant increase of dead plant tissues provides a final dose of energetic molecules that can be used by the pathogen to complete its life cycle. Our hypothesis is summarized in the Fig. 10.

\section{Conclusions}

PpCRN7 and PpCRN20 are associated with the aggressiveness of $P$. parasitica as well as enhancing susceptibility of plants, therefore their mechanisms are now targets of biotechnological studies aiming to disrupt the activity of these effectors breaking pathogen's aggressiveness and to promote plant resistance. Another approach will be to identify and edit the plant molecular targets or susceptibility genes that these effectors act upon, also resulting in resistance.

\section{Methods}

\section{Oomycete growth conditions}

Phytophthora parasitica isolate 'IAC_01/95.1' (stored in the microorganisms collection of the IAC-CordeiropolisSP Brazil) was grown in a carrot-agar medium, at $25^{\circ} \mathrm{C}$ in the dark. Sporangia development was performed according to Máximo et al. (2017) [11, 21, 22]. Briefly, after colony reaching up to $80 \%$ of the plate capacity, sporangia development were induced by pouring sterile water on plate, replacing water daily for one week. To induce zoospores release, plates were incubated at $4{ }^{\circ} \mathrm{C}$, in the dark, during one hour. Zoospore suspension was collected and adjusted to a concentration of $10^{5}$ zoospores/ $\mathrm{mL}$. The amount of zoospores in suspension was counted in a Neubauer chamber.

\section{Plant infection and agroinfiltration assay}

Seeds of "Sunki" mandarin (Citrus sunki Hort. Ex Tan.) and trifoliate orange (Poncirus trifolita (L.) Raf. cv, Rubidoux) were obtained from the collection of the active citrus germplasm bank of Centro de Citricultura Sylvio Moreira/Instituto Agronômico de Campinas (CCSM/IAC), Cordeirópolis, São Paulo, Brazil. Seeds of Citrus sunki and Poncirus trifoliata were germinated in sterile soil. Three months after germination, the substrate was carefully removed and the seedlings transferred to Falcon tubes containing $50 \mathrm{~mL}$ of distilled water. A suspension of $10^{5}$ zoospore $/ \mathrm{mL}$ was added to the recipient and sealed with Parafilm to reduce losses through evaporation. Plants were incubated in growth chamber at $20^{\circ} \mathrm{C}$ under photoperiod of $12 \mathrm{~h}(250 \mu \mathrm{mol} \mathrm{m}-2$ s-1). Six biological replicates for each treatment were used 


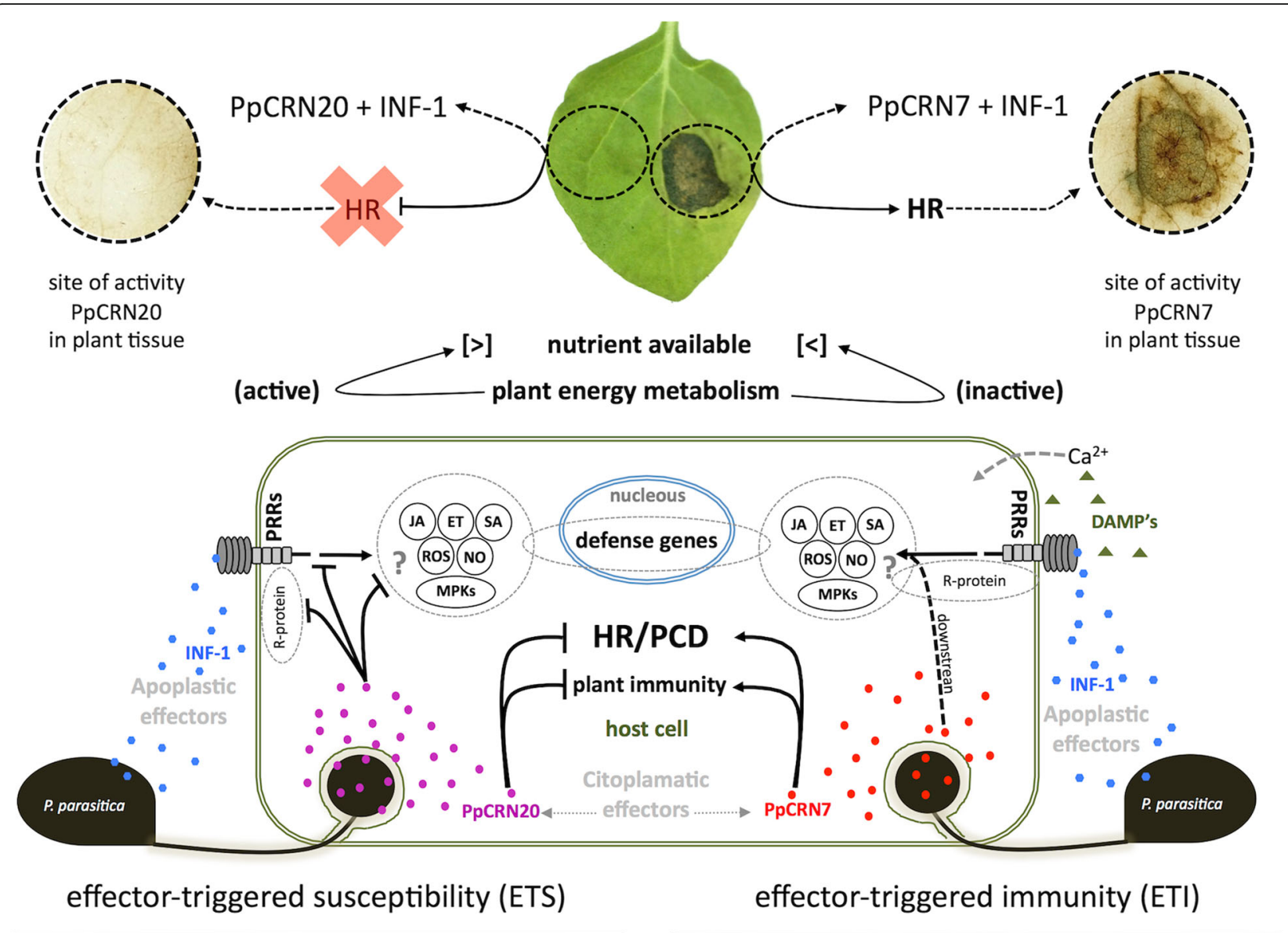

Fig. 10 Schematic model of the interaction between P. parasitica and host plants, including the biological role of PpCRN7 and PpCRN20 effectors. On left, figure represents the PpCRN20 acting on hypersensitive response (HR) and cell-death suppression. On right, figure represents the PpCRN7 acting synergistically with the elicitin INF-1 to promote and potentiate HR and subsequent PCD. The sites of activity of the effectors PpCRN20 and PpCRN7 are highlighted by DAB assay

and the assay repeated two times. Plant roots samples were harvested $0,3,6,394.12,24,48$ and $96 \mathrm{~h}$ post inoculation (hpi) to analyse the expression of putative $P p C R N$ genes from $P$. parasitica. These time points were selected in accordance to the $P$. parasitica hemibiotrophic life style, described previously $[11,21,22]$. $N$. benthamiana seeds were obtained from the seed bank collection of Centro de Citricultura Sylvio Moreira/Instituto Agronômico de Campinas (CCSM/IAC), Cordeirópolis, São Paulo, Brazil. The agroinfiltration assays were carried out with plants of 4-6 weeks old of $N$. benthamiana. The plants were grown under 16/8 h (light/dark) photoperiod at $22-25^{\circ} \mathrm{C}, 60 \%$ humidity with $200 \mu \mathrm{mol} m-2 \mathrm{~s}-1$ illumination during the day period. Young and fully expanded leaves were used.

\section{Identification and annotation of $P$. parasitica candidate CRN effector genes}

Candidate CRN effector sequences from $P$. parasitica isolate 'IAC_01/95.1' (PpCRN) were identified as following: (i) identification of protein sequences that belongs to CRN family deposited in the Uniprot database; (ii) search for homologous sequences in the genome of isolate 'IAC_01/ 95.1', using sequences identified in the Uniprot database as query for BLAST analysis (BlastP e-value $>1 \mathrm{e}-05$ ); (iii) PpCRN protein sequences were analyzed for the identification of conserved domains, and for the presence/absence of transmembrane domains using the TMHMM 2.0 software (http: //www.cbs.dtu.dk / services / TMHMM /); (iv) identification of peptide signals by SignalP 3.0 software (http://www.cbs.dtu.dk/services/SignalP-3.0/), and for prediction of the subcellular localization, using the WoLF PSORT software (http://wolfpsort.org/); and (v) PpCRN protein sequences were aligned and grouped by similarity using the cluster analysis and the neighborjoining method. These analyses were also performed using public available sequences under the "Phytophthora parasitica genome initiative", corresponding to the genomes: 'P1569.1', 'P1976.1', 'INRA-310.3', 'P10297.1', 'CJ01A1.1', 'CJ05E6.1', 'CHvinca01.1', 'CJ02B3.1' in order to identify the number of putative CRNs candidates in these isolates. 
The description of all $P$. parasitica putative CRN protein sequences is present in the Additional file 1. The CRN candidate sequences, namely PpCRN (Phytophthora parasitica Crinkler) were followed by the numerical order of appearance in our in silico analysis.

The presence of similar CRN effectors in the genomes of other $P$. parasitica isolates was verified applying a Blastp search using the protein sequences of the 80 PpCRN candidates from 'IAC_01/95.1' genome as query. For this analysis, a minimum protein sequence identity and coverage values of 95 and $50 \%$, respectively, were set. The number of genes, frequency, geographical origin of the $P$. parasitica isolates and hosts are shown in Table 1 .

\section{Genome architecture of $P$. parasitica}

Distribution of 80 predicted $P p C R N$ effectors in the 'IAC 01_95' genome was carried out by genome architecture analysis, based on two dimensional method of binary data using $\mathrm{R}$ software. This method is flexible a combines genome architecture heatmaps with scatter plots of the genomic environment and the pool of selected genes [44].

\section{Plasmid design and agro-transformation}

Gene sequences of $P p C R N 7$ and $P p C R N 20$ fused to a 3xHA tag were obtained by gene synthesis and cloned in the vector pCambia 1302 (Additional File 2 and Additional file 5: Figure S3). The recombinant plasmids were sequenced and used for transformation of Agrobacterium tumefaciens GV3101. Transformed agrobacterium were cultivated in LB agar plates supplemented with kanamycin $50 \mu \mathrm{g} / \mathrm{mL}$ and rifampicin $50 \mu \mathrm{g} / \mathrm{mL}$ for $2-3$ days at $28^{\circ} \mathrm{C}$. From a single colony on LB plate, we prepared a pre-inoculum of agrobacterium in $3 \mathrm{~mL}$ liquid LB medium with antibiotics for $24 \mathrm{~h}$ at $28^{\circ} \mathrm{C}$ and $200 \mathrm{RPM} .40 \mu \mathrm{L}$ of the pre-inoculum was taken to get an inoculum of 10-15 mL YEB (Agrobacterium growth medium) with same antibiotics, $2 \mu \mathrm{M}$ acetosyringone and $10 \mathrm{mM}$ MES and growth overnight till it reached the final OD of approximately 1 . The bacteria in the medium were precipitated $(4000 \times \mathrm{g}, 10 \mathrm{~min})$, and the pellet resuspended in MMA medium $20 \mathrm{~g}$ sucrose, $5 \mathrm{~g}$ MS salts, $1.95 \mathrm{~g}$ MES, $\mathrm{pH}$ adjusted to 5.6 with $\mathrm{NaOH}$, and $1 \mathrm{ml}$ acetosyringone/L). Final $\mathrm{OD}_{600 \mathrm{~nm}}$ was adjusted to $0.5-1.0$. The cells were incubated at room temperature for $3 \mathrm{~h}$. Infiltrations were performed with $1 \mathrm{~mL}$ syringe by pressing the needleless syringe on the underside of the leaf. Plants were incubated at $25^{\circ} \mathrm{C}$ in an $12 \mathrm{~h}$ photoperiod. Symptoms were observed 2-7 days after infiltration. PpCRN7- and $P p C R N 20$-containing vectors were co-infiltrated with INF-1containg vector. These assays were repeated three times.

\section{Detection of reactive oxygen species (ROS) in plant tissue to evaluate $\mathrm{HR}$}

For detecting ROS, specifically $\mathrm{H}_{2} \mathrm{O}_{2}$ in leaves of $N$. benthamiana, it was carried out the DAB assay at 5 days post infiltration according to Thordal-Christensen et al. (1997) [45] and Salzer et al. (1999) [46]. The stained leaves were analyzed by light-microscopy.

\section{$P$. parasitica inoculation and quantification of their DNA in plant to asses disease development}

To evaluate the activity of the PpCRN7 and PpCRN2O during the colonization and development of $P$. parasitica in $N$. benthamiana leaves, we performed agroinfiltration of candidate effectors followed by zoospores inoculation (24h after agroinfiltration). $1 \times 10^{6} P$. parasitica zoospores were inoculated in agroinfiltrated spots. Leaves agroinfiltrated with empty vector used as controls. Three biological replicates were used for each treatment. The leaves were harvested $72 \mathrm{hpi}$, after emergence of symptoms to evaluate the amount of genomic DNA of $P$. parasitica. Fresh mycelia from carrot solid medium (100 $\mathrm{mg}$ ) was grounded in liquid nitrogen and preceded to DNA isolation and purification using DNeasy plant mini kit (Qiagen). DNA was further purified with Wizard ${ }^{\circ}$ Kit (Promega) according to the manufacturer's recommendation. DNA samples were evaluated for purity and

Table 1 Genomes publicly available of Phythophthora parasitica. Different isolates of P. parasitica, whose genomes are sequenced and publicly available, indicating their number of genes, geographic origin, and their respective host plants

\begin{tabular}{|c|c|c|c|c|}
\hline Isolate/Genome* & Number of genes & $\%$ & Origin & Host \\
\hline P1569.1 & 23.159 & 100 & California & Citrus \\
\hline P1976.1 & 23.127 & 99.8 & California & Tomato \\
\hline INRA-310.3 & 23,121 & 99.8 & Australia & Tobacco \\
\hline P10297.1 & 23.114 & 99.8 & Florida & Dieffenbachia exotica \\
\hline CJ01A1.1 & 23.061 & 99.5 & Virginia & Tobacco \\
\hline CJ05E6.1 & 21.812 & 94.1 & Virginia & Tobacco \\
\hline IAC_01/95.1 & 21.789 & 94.0 & São Paulo & Citrus \\
\hline CHvinca01.1 & 21.679 & 93.6 & Virginia & Periwinkle \\
\hline CJ02B3.1 & 21.085 & 91.0 & Virginia & Tobacco \\
\hline
\end{tabular}

*Phytophthora parasitica Assembly Dev initiative, Broad Institute (broadinstitute.org) 
concentration by ultraviolet spectroscopy (NanoDrop 8000, Thermo Scientific). RT-qPCR was performed with a mixture of diluted DNA $\left(1: 20 \mathrm{H}_{2} \mathrm{O}\right)$, GoTaq ${ }^{\circ}$ RealTime qPCR (Promega) and $10 \mathrm{pmol}$ of each primer PN5b (5'GAACAATGCAACTTATTGGACGTT3') and PN6 (5' AACCGAAGCTGCCACCCTAC3') (ITS regions) in a final volume of $20 \mu \mathrm{L}$ [47]. Reactions were carried out with the following thermal cycler program, an initial denaturation at $95^{\circ} \mathrm{C}$ for $10 \mathrm{~min}$ and 40 cycles: $95^{\circ} \mathrm{C} 15 \mathrm{~s}, 62^{\circ} \mathrm{C} 60 \mathrm{~s}$. The $\mathrm{Ct}$ values were plotted in a standard curve generated from a sample with known DNA concentration, to determine the concentration of DNA in the evaluated sample. The concentration of DNA in the standard curve ranged from $1 \mathrm{pg}$ to $10 \mathrm{ng}$ DNA $\mathrm{mL}-1$. The results were analysed with KruskalWallis [48] and Wilcoxon test [49].

\section{Protein extraction and western blot analysis}

Leaf tissues of $N$. benthamiana were grounded to a fine powder under liquid nitrogen using a sterile mortar and pestle and rinsed with extraction buffer (Hepes $50 \mathrm{mM}$, KCL $150 \mathrm{mM}$, EDTA $1 \mathrm{mM}$, Triton X-100 0.1\%, with pH adjusted to 7.5 with $\mathrm{KOH}$ ) supplemented with $1 \mathrm{mM}$ DTT and protease inhibitor. Total protein extracts were transferred to $15 \%$ SDS-polyacrylamid gels, and the pattern of bands further analyzed. Proteins were transferred to a nitrocellulose membrane, and membranes were washed in PBST (PBS with 0.1\% Tween 20) during 2 min and blocked during $30 \mathrm{~min}$ in PBST-BSA (PBS with $0.1 \%$ Tween 20 and $3 \%$ bovine serum albumin (BSA)). Rabbit anti-HA monoclonal antibody was added to the PBSTBSA buffer and incubated for $20 \mathrm{~min}$ using the method SNAP i.d. 2.0 Protein Detection System, followed by washing steps with PBST (three times). Membranes were then incubated in PBST-BSA in addition to the chemiluminescent secondary antibody reactive to luminol. The immunoreactive bands were detected on x-ray film by enhanced chemiluminescence with luminol substrate and subsequently photoregistrated.

\section{Supplementary information}

Supplementary information accompanies this paper at https://doi.org/10. 1186/s12870-019-2129-8.

Additional file 1. Sequences and additional information of the Crinkler candidates .xls (1,8 MB).

Additional file 2. Nucleotide sequences of the CRN's effectors PpCRN7 and PpCRN20 used for transformation .pdf (67 KB).

Additional file 3. Fig. 1: Sequence alignment of amino acid sequences of PpCRN7 and ppCRN20 from P. parasitica isolates .TIFF (18,7 MB).

Additional file 4. Fig. 2: PpCRN gene expression analysis during $P$. parasitica interaction with C. sunki and P. trifoliata .TIFF $(20,4 \mathrm{MB})$.

Additional file 5. Fig. 3: Plant-expressing vector used for the functional characterization of PpCRN genes and validation of protein expression .TIFF $(12,7 \mathrm{MB})$.
Additional file 6. Fig. 4: Transient expression of PpCRN7 in N. benthamiana leaves. TIFF (11,4 MB).

\section{Abbreviations}

${ }^{\circ} \mathrm{C}$ : degrees Celsius; Anti-HA: anti-Hemagglutinin (antibody); $\mu \mathrm{g}:$ microgram; $\mu \mathrm{L}$ : Microliter; $\mu \mathrm{M}$ : micromolar; Ca2 + : Calcium ion; CBEL: Cellulose-Binding, Elicitor and Lectin activity; CHvinca01.1: Phytophthora parasitica isolate/ genome; CJ01A1.1: Phytophthora parasitica isolate/genome;

CJ02B3.1: Phytophthora parasitica isolate/genome; CJ05E6.1: Phytophthora parasitica isolate/genome; CRN: effector of the Crinkler family; DAB: 3,3'diaminobenzidine; DAMPs: Damage-Associated Molecular Patterns; DI: motif of protein Crinkler; DTT: DL-Dithiothreitol; DWL: motif of protein Crinkler; EDTA: Ethylenediaminetetraacetic acid; ERF1: ethylene response factor 1; ET: Ethylene; ETS: effector-triggered susceptibility; EV: Empty Vector; FW: fresh weight; g: gram; GV3101: Agrobacterium tumefaciens strain; h: hours; $\mathrm{H}_{2} \mathrm{O}_{2}$ : Hydrogen peroxide; hpi: hours post inoculation; HR: Hypersensitivity Response; HVLVXXP: motif of protein Crinkler; IAC_01/95.1: Phytophthora parasitica isolate/genome; INF-1: elicitin 1 of Phytophtora infestans; INRA310.3: Phytophthora parasitica isolate/genome; JA: Jasmonate; KCL: Potassium chloride; KOH: Potassium hydroxide; L: Litre; LB: Luria-Bertani medium Leucine-Alanine-Lysine; LFLAK: LxLFLAK-like motif; LOX: (Protein Coding), Lysyl Oxidase; LXLFLAK: motif of protein Crinkler Leucine-any amino acidPhenylalanine; LYLATK: LXLFLAK-like motif; MES: MES Medium; mg: Milligram; mL: millilitre; mM: millimolar; MMA: MMA Medium; MPKs: Mitogen-Activated Protein Kinases; $\mathrm{NaOH}$ : Sodium hydroxide; ng: nanogram; NO: Nitric oxide; NPP-1: Necrosis-inducing Phytophthora Protein 1; OD: Optical Density; P10297.1: Phytophthora parasitica isolate/genome; P1569.1: Phytophthora parasitica isolate/genome; P1976.1: Phytophthora parasitica isolate/genome; PAMPs: Pathogen-Associated Molecular Patterns; pb: base pair;

PBS: Phosphate-buffered saline; PCD: Programmed Cell Death; pg: picogram; pH: potential of hydrogen; PiCRN8: Phytophthora infestans Crinkler number 8; PN5b: pimer pair name (Phytophthora nicotianae 5b); PN6: pimer pair name (Phytophthora nicotianae 6); PpCRN: candidate Crinkler effectors in

Phytophthora parasitica genomes; PpCRN: genes encoding Crinkler effector proteins in the genome of $P$. parasitica; PpCRN20: Phytophthora parasitica Crinkler effector proteins number 8; PpCRN7: Phytophthora parasitica Crinkler effector proteins number 7 ; PR1b: Pathogenesis-related protein $1 \mathrm{~b}$; PR2b: Pathogenesis-related protein 2b; PRRs: Pattern Recognition Receptors; PsCRN115: Phytophthora sojae Crinkler number 115; PsCRN63: Phytophthora sojae Crinkler number 63; PTI: Pattern-Triggered Immunity; ROS: reactive oxygen species; RPM: rotations per minute; RT-qPCR : Quantitative reverse transcription Polymerase Chain Reaction; RxLR: effector of the RxLR family; S3A: 40 S ribosomal protein S3a; SA: Salicylic acid; SDS: sodium dodecyl sulfate; UBC: Ubiquitin-conjugating enzyme; YEB: Yeast Extract Beef medium; umol $m-2 s-1$ : Micromole per second and square meter

\section{Acknowledgements}

We thank Msc. Tiago Silva Oliveira and Dra. Michèle Claire Breton for providing comments that improved the text. This work is part of Heros José Máximo Ph.D. thesis in the Department of Functional and Molecular Biology, State University of Campinas, Brazil.

\section{Authors' contributions}

HJM contributed in all biological assay, plant infection and agro-infiltration assay, identification and annotation of $P$. parasitica candidate $C R N$ effector genes, genome architecture of $P$. parasitica, plasmid design and agrotransformation, detection of reactive oxygen species, P. parasitica inoculation and quantification in plant, protein extraction and western blot analysis, statistical analysis. RJDD contributed in co-supervision and construction of research, experimental design, plasmid design and agro-transformation, $P$. parasitica inoculation and quantification in plant, and protein extraction and western blot analysis. ROD contributed effectively in the identification and annotation of $P$. parasitica candidate CRN effector genes, and genome architecture of $P$. parasitica. HLF contributed effectively in the design and statistical analysis employed statistical model and data compilation. MAM contributed effectively in supervision and construction of research and experimental design. MAM, CGL, ROD, RJDD and HJM analysed the data and wrote the manuscript. All authors read and approved the final manuscript. 


\section{Funding}

This work was supported by Fundação de Amparo a Pesquisa no Estado de São Paulo (FAPESP 2015/14498-6), Conselho Nacional de Desenvolvimento Científico e Tecnológico (CNPq 445390/2014-0 and 465440/2014-2) and Fundação Nacional de Desenvolvimento de Ensino Superior Particular (FUNADESP 8800105/2018-0005-R172). The role of the funding body is to provide financial support. The funders had no role in study design, data collection and analysis, decision to publish, or preparation of the manuscript.

\section{Availability of data and materials}

All data generated or analysed during this study are included in this published article and its supplementary information files. The analysis were performed using public sequences available under the [Phytophthora parasitica genome initiative], [https://www.ncbi.nlm.nih.gov/assembly/?term= phytophthora\%20parasitica] and [UniProt] [https://www.uniprot.org/].

\section{Ethics approval and consent to participate}

'Not applicable' in this section.

\section{Consent for publication}

'Not applicable' in this section.

\section{Competing interests}

All the authors declare that they have no competing interest (s) which can interfere in the judgement of analysing and interpreting the results of this study.

\section{Author details}

'Biotechnology Laboratory, Centro de Citricultura Sylvio Moreira/Instituto Agronômico (IAC), Cordeirópolis, SP, Brazil. ${ }^{2}$ Instituto de Química, Universidade de São Paulo (USP), São Paulo, SP, Brazil. ${ }^{3}$ Instituto de Matemática, Física e Computação Científica, Universidade Estadual de Campinas (UNICAMP), Campinas, SP, Brazil.

\section{Received: 11 July 2018 Accepted: 8 November 2019}

\section{Published online: 06 December 2019}

\section{References}

1. Stassen JHM, Van den Ackerveken G. How do oomycete effectors interfere with plant life? Current Opinion in Plant Biology. 2011, 14-407-414.

2. Birch PR, Rehmany AP, Pritchard L, Kamoun S, Beynon JL. Trafficking arms: oomycete effectors enter host plant cells. Trends Microbiol. 2006;14:8-11.

3. Oliva R, Win J, Raffaele S, Boutemy L, Bozkurt TO, et al. Recent developments in effector biology of filamentous plant pathogens. Cellular Microbiology. 2010;12:705-15.

4. Hein I, Gilroy EM, Armstrong MR, Birch PR. The zig-zag-zig in oomyceteplant interactions. Mol Plant Pathol. 2009;10:547-62.

5. Jones JDG, Dangl JL. The plant immune system. Nature. 2006, [s.I.], v. 444, n. 7117, p.323-329.

6. Lamour K. Kamoun S. Diversity, Interactions, and Research Tools. New Jersey- John Wiley \& Sons: Oomycete Genetics and Genomics; 1997.

7. Kroon LP, Brouwer $H$, de Cock AW, Govers F. The genus Phytophthora anno 2012. Phytopathology 2012, 102-348-364.

8. Lamour KH, Stam R, Jupe J, Huitema E. The oomycete broad-host-range pathogen Phytophthora capsici. Molecular Plant Pathology. 2012, 13-329-337.

9. Luz E. Doenças causadas por Phytophthora no Brasil. Campinas: Editora Rural. 2001;1:1-22.

10. Graham, J, Feichtenberger, E. Citrus-phytophthora diseases: Management challenges and successes. Journal of Citrus Pathology. 2015, iocv_ journalcitruspathology_27203.

11. Dalio, RDD, Máximo, HJ, Oliveira, TS, Azevedo, TM, Felizatti, HL, Camopos, MA, Machado, MA. Molecular basis of Citrus sunki susceptibility and Poncirus trifoliato resistance upon Phytophthora parasitica attack. Molecular Plant-Microbe Interactions, 2018, 31, 3, 386-398. https://doi.org/10.1094/MPMI-05-17-0112-Fl

12. Dalio, RJD, Magalhães, DM, Rodrigues, CM, Arena, GD, Oliveira, TS, SouzaNeto, RR, Picchi, SC, Martins, PMM, Santos, PJC, Maximo, HJ, Pacheco, IS, De Souza, AA, Machado, MA. PAMPs, PRRs, effectors and R-genes associated with citrus-pathogen interactions, Annals of Botany. 2017, Volume 119, Issue 5, 1 Pages 749-774, https://doi.org/10.1093/aob/mcw238.

13. Kamoun S. A catalogue of the effector secretome of plant pathogenic oomycetes. Annu Rev Phytopathol. 2006;44:41-60.
14. Hogenhout SA, Van der Hoorn RA, Terauchi R, Kamoun S. Emerging concepts in effector biology of plant-associated organisms. Mol PlantMicrobe Interact. 2009;22:115-22.

15. Haas BJ, Kamoun S, Zody MC, Jiang RH, Handsaker RE, Cano LM, Grabherr M, Kodira CD, Raffaele S, Torto-Alalibo T, et al. Genome sequence and analysis of the Irish potato famine pathogen Phytophthora infestans. Nature. 2009;461:393-8.

16. Tyler B, Tripathy S, Zhang X, Dehal P, Jiang R, et al. Phytophthora genome sequences uncover evolutionary origins and mechanisms of pathogenesis. Science. 2006;313:1261-6.

17. Morgan W, Kamoun S. RXLR effectors of plant pathogenic oomycetes. Curr Opin Microbiol. 2007;10:332-8.

18. Amaro TMMM, Thilliez GJA, Motion GB, Huitema E. A perspective on CRN proteins in the genomics age: evolution, classification. Delivery and Function Revisited Front Plant Sci. 2017:8:99. https://doi.org/10.3389/fpls.2017.00099.

19. Rajput NA, Zhang MX, Ru YY, Liu TL, Xu J, Liu L, et al. Phytophthora sojae effector PsCRN70 suppresses plant defenses in Nicotiana benthamiana. PLoS One. 2014;9:e98114.

20. Zhang MX, Rajput NA, Shen DY, Sun P, Zeng WT, Liu TL, et al. A Phytophthora sojae cytoplasmic effector mediates disease resistance and abiotic stress tolerance in Nicotiana benthamiana. Sci Rep. 2015:5:10837.

21. Máximo HJ, Dalio RJD, Rodrigues CM, Breton MC, Machado MA. Reference genes for RT-qPCR analysis in Citrus and Poncirus infected by zoospores of Phytophthora parasitica. Tropical Plant Pathology. 2017;42:76.

22. Dalio, RJD, Máximo, HJ, Oliveira, TS, Dias, RO, Breton, MC, Felizatti, HL, Machado, MA. Phytophthora parasitica Effector PpRxLR2 Suppresses Nicotiana benthamiana Immunity. Molecular Plant-Microbe Interactions. 2018, 31, 4, 481-493. https://doi.org/10.1094/MPMI-07-17-0158-Fl.

23. Kamoun S, van West P, Vleeshouwers VGAA, de Groot KE, Govers F. Resistance of Nicotiana benthamiana to Phytophthora infestans is mediated by the recognition of the elicitor protein INF1 the plant cell. Vol. 1998;10:1413-25.

24. Goodwin SB. The population genetics of Phytophthora. Phytopathology. 1997;87:462-73. 18945128

25. Raffaele S, Sophien K. Genome evolution in filamentous plant pathogens: why bigger can be better. Nat Rev Microbiol. 2012;10:417-30.

26. Anderson JP, Gleason CA, Foley RC, Thrall PH, Burdon JB, Singh KB. Plants versus pathogens: an evolutionary arms race. Funct Plant Biol. 2010;37:499-512

27. Cline ET, Farr DF, Rossman AY. Synopsis of Phytophthora with accurate scientific names, host range, and geographic distribution. Plant Health Progress. 2008. https://doi.org/10.1094/PHP-2008 0318-01-RS.

28. Lin $\mathrm{K}$, et al. Single nucleus genome sequencing reveals high similarity among nuclei of an Endomycorrhizal fungus. PLoS Genet. 2014:10:1-13.

29. Stam, R, Jupe, J, Howden, AJM, Morris, J. A, Boevink, PC, Hedley, PE, and Huitema, E. Identification and Characterisation CRN Effectors in Phytophthora capsici Shows Modularity and Functional Diversity. PLoS One. 2013, 8: e59517

30. Sun G, Yang Z, Kosch T, Summers K, Huang J. Evidence for acquisition of virulence effectors in pathogenic chytrids. BMC Evol Biol. 2011;11:195.

31. Kemen E, Gardiner A, Schultz-Larsen T, Kemen AC, Balmuth AL, RobertSeilaniantz A, Bailey K, Holub E, Studholme DJ, Maclean D, Jones JDG. Gene gain and loss during evolution of obligate parasitism in the white rust pathogen of Arabidopsis thaliana. PLoS Biol. 2011;9:e1001094.

32. Links MG, Holub E, Jiang RHY, Sharpe AG, Hegedus D, Beynon E, Sillito D, Clarke WE, Uzuhashi S, Borhan MH. De novo sequence assembly of Albugo candida reveals a small genome relative to other biotrophic oomycetes. BMC Genomics. 2011;12:503.

33. Levesque CA, Brouwer $\mathrm{H}$, Cano L, Hamilton JP, Holt C, Huitema E, Raffaele S, Robideau GP, Thines M, Win J, et al. Genome sequence of the necrotrophic plant pathogen Pythium ultimum reveals original pathogenicity mechanisms and effector repertoire. Genome Biol. 2010;11:pR73.

34. Baxter L, Tripathy S, Ishaque N, Boot N, Cabral A, Kemen E, Thines M, Ah-Fong A, Anderson R, Badejoko W, et al. Signatures of adaptation to obligate biotrophy in the Hyaloperonospora arabidopsidis genome. Science. 2010;330:1549-51.

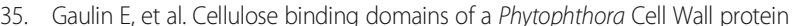
are novel pathogen-associated molecular patterns. Plant Cell. 2006;18:1766-77.

36. Schornack, S, van Damme, M, Bozkurt, T. O, Cano, L. M, Smoker, M, Thines, $M$, et al. Ancient class of translocated oomycete effectors targets the host nucleus. Proc. Natl. Acad. Sci. U.S.A. 2010, 107, 17421-17426.

37. Liu T, Ye W, Ru Y, Yang X, Gu B, Tao K, et al. Two host cytoplasmic effectors are required for pathogenesis of Phytophthora sojae by suppression of host defenses. Plant Physiol. 2011;155:490-501. 
38. Zhang MX, Li Q, Liu TL, Liu L, Shen DY, Zhu Y, et al. Two cytoplasmic effectors of Phytophthora sojae regulate plant cell death via interactions with plant catalases. Plant Physiol. 2015;167:164-75.

39. Shen DY, Liu TL, Ye WW, Liu L, Liu PH, Wu YR, et al. Gene duplication and fragment recombination drive functional diversification of a superfamily of cytoplasmic effectors in Phytophthora sojae. PLoS One. 2013;8:e70036.

40. Stam R, Howden AJM, Delgado-Cerezo M, Amaro TMMM, Motion GB, Pham J, et al. Characterization of cell death inducing Phytophthora capsici CRN effectors suggests diverse activities in the host nucleus. Front Plant Sci. 2013;4:387.

41. Attard A, Evangelisti E, Kebdani-Minet N, Panabières F, Deleury E, Maggio C, Ponchet $\mathrm{M}$, Gourgues M. Transcriptome dynamics of Arabidopsis thaliana root penetration by the oomycete pathogen Phytophthora parasítica. BMC Genomics. 2014;15:538.

42. Boava LP, Cristofani-Yaly M, Mafra VS, Kubo K, Kishi LT, Takita MA, RibeiroAlves M, Machado MA. Global gene expression of Poncirus trifoliata Citrus sunki and their hybrids under infection of Phytophthora parasitica. BMC Genomics. 2011;12:39.

43. Evangelisti E, Govetto B, Minet-Kebdani N, Kuhn ML, Attard A, Ponchet M, Panabieres F, Gourgues M. The Phytophthora parasitica RXLR effector penetration-specific effector 1 favours Arabidopsis thaliana infection by interfering with auxin physiology. The New phytologist. 2013;199:476-89.

44. Raffaele S, Win J, Cano LM, Kamoun S. Analyses of genome architecture and gene expression reveal novel candidate virulence factors in the secretome of Phytophthora infestans. BMC Genomics. 2010;11:637. https://doi.org/10. 1186/1471-2164-11-637.

45. Thordal-Christensen $\mathrm{H}$, Zhang $Z$, Wei $Y$, Collinge DB. Subcellular localization of $\mathrm{H}_{2} \mathrm{O}_{2}$ in plants. $\mathrm{H}_{2} \mathrm{O}_{2}$ accumulation in papillae and hypersensitive response during the barley—powdery mildew interaction. Plant J. 1997;11:1187-94.

46. Salzer P, Corbière H, Boller T. Hydrogen peroxide accumulation in Medicago truncatula roots colonized by the arbuscular mycorrhiza-forming fungus Glomus intraradices. Planta. 1999;208:319-25.

47. Ippolito A, Schena L, Nigro F. Detection of Phytophthora nicotianae and $P$ citrophthora in citrus roots and soils by nested PCR. European Journal of Plant Pathology. 2002;108:855-68.

48. Kruskal HW, Wallis AW. Use of ranks in one-criterion variance analysis. J Am Stat Assoc. 1952:47(260):583-621.

49. Bauer DF. Constructing confidence sets using rank statistics. J Am Stat Assoc. 1972;67:687-90.

\section{Publisher's Note}

Springer Nature remains neutral with regard to jurisdictional claims in published maps and institutional affiliations.

Ready to submit your research? Choose BMC and benefit from:

- fast, convenient online submission

- thorough peer review by experienced researchers in your field

- rapid publication on acceptance

- support for research data, including large and complex data types

- gold Open Access which fosters wider collaboration and increased citations

- maximum visibility for your research: over $100 \mathrm{M}$ website views per year

At $\mathrm{BMC}$, research is always in progress.

Learn more biomedcentral.com/submissions 